Brazilian Journal

of Chemical

Engineering

\title{
FUNCTIONALIZED GRAPHENE-BASED MATERIALS AS INNOVATIVE ADSORBENTS OF ORGANIC POLLUTANTS: A CONCISE OVERVIEW
}

\author{
Tiago J. M. Fraga ${ }^{1 *}$, Marilda N. Carvalho ${ }^{1}$, Marcos G. Ghislandi ${ }^{2}$ \\ and Maurício A. da Motta Sobrinho ${ }^{1}$

\begin{abstract}
${ }^{1}$ Universidade Federal de Pernambuco, Departamento de Engenharia Química, Recife/PE, Brasil. E-mail: tiago.fraga2012@gmail.com,
${ }^{2}$ Universidade Federal Rural de Pernambuco, Unidade Acadêmica do Cabo de Santo Agostinho, Cabo de Santo Agostinho/PE, Brasil.
\end{abstract} \\ ORCID: 0000-0002-5683-7307; marildacarv@gmail.com, ORCID: 0000-0001-7872-6432; mottas@ufpe.br, ORCID: 0000-0003-2638-9096 \\ E-mail: ghislandi@gmail.com, ORCID: 0000-0001-7415-7260
}

(Submitted: June 25, 2018 ; Revised: August 5, 2018 ; Accepted: August 28, 2018)

\begin{abstract}
The functionalization of graphene nanosheets is the cutting edge of materials sciences nowadays. Such research promotes the development of innovative, low cost and highly capable sorbents. This review article aims to assemble the available information on functionalized graphene used for the adsorption of organic pollutants and establishes a critical comparison between the data reported in the literature. Various optimal experimental conditions $(\mathrm{pH}$, temperature, contact time, adsorbent dosage) and adsorbent characterization methods (FTIR, Raman, XPS spectra, XRD, TEM and AFM) have been listed to enlighten adsorption mechanisms, capacity and limiting aspects. Moreover, adsorption isotherms, kinetics and thermodynamic data of different functionalized graphene-based materials towards a wide range of organic pollutants were analyzed and tabulated. In each evaluation topic, environmental and human health protection is subject for discussion, as well as the scientific breakthrough works available in high impact journals in the field.

Keywords: Adsorption; Graphene; Functionalization; Atmospheric; Wastewater; Organic pollutants.
\end{abstract}

\section{INTRODUCTION}

The development of new graphene-based engineering materials is at the cutting edge among recent research in chemical and materials engineering. There are two ways to insert functional groups on the graphene nanosheet surface via chemical routes: by covalent or non-covalent functionalization. Graphene covalent chemical functionalization creates covalent bonds by converting $\mathrm{sp}^{2}$ into $\mathrm{sp}^{3}$ orbitals (Daukiya et al., 2017; Vecera et al., 2017); however, surface enhancement can also be achieved by noncovalent functionalization, in which there are weak intermolecular interactions between the ligand and graphene structural elements, such as dipole-dipole and van der Waals forces (Punetha et al., 2017).
The functionalization of graphene or graphene oxide (GO) nanosheets confers specific properties to the composites, e.g., their chemical selectiveness, solubility, thermal and electronic conductivity (Bueno et al., 2017; Xiang et al., 2016). Such enhancement allows the employment of functionalized graphenebased materials in several fields, such as chemistry and catalysis (Ye et al., 2018; Rana and Jonnalagadda, 2017), biomedicine (Kenry et al., 2018; Yu et al., 2018; Zeng et al., 2017), electronics (Scidà et al., 2018; Gevaerd et al., 2018; Chiu et al., 2017; Zhao et al., 2017), energy (Li and Zhi, 2018; Sadri et al., 2017) and environmental sciences and technologies (Ren et al., 2018; Othman et al., 2018; Khurana et al., 2018). Due to their large specific surface area and rich porous structure, carbonaceous materials usually show

\footnotetext{
* Corresponding author: Tiago J. M. Fraga - E-mail: tiago.fraga2012@gmail.com
} 
high adsorption capacity and have been successfully employed as adsorbents of organic pollutants (Zhang et al., 2017). Functional moieties distributed on the graphene surface and edges facilitate sorbent-sorbate specific interactions, which depend on the pollutant structure. In this sense, discovering the nature of the forces involved is crucial for enhancing the adsorbent selectiveness and performance (Kyhl et al., 2018). The most reported interactions are $\pi-\pi$ stacking, electrostatic, van der Waals forces and H-bonds (Xue et al., 2018; Das et al., 2017; Wang et al., 2017a).

The most toxic and dangerous organic pollutants discharged into the environment, which have been object of study for adsorption onto graphene-based nanomaterials, are listed as follows: organic dyes (Das et al., 2018; Ganesan et al., 2018), polycyclic aromatic hydrocarbons (Yang et al., 2015), pharmaceuticals (Akpotu and Moodley, 2018; Rostamian and Behnejad, 2018), pesticides (Zhang et al., 2015; Maliyekkal et al., 2013), herbicides (Liu et al., 2016; $\mathrm{Wu}$ et al., 2015), oil-derived products (Huang and Yan, 2018; Xia et al., 2018; Xiao et al., 2018) and volatile organic compounds (VOCs) (Chen and Chen, 2015). These compounds frequently present aromatic rings in their structure, hence they have the property to degrade and deliver carcinogenic and mutagenic products in water bodies and the atmosphere (Zhang et al., 2017; Carvallho et al., 2016). Furthermore, the bioaccumulation of products such as pharmaceuticals, pesticides, plasticizers, hormones and their by-products in water bodies may also generates microbial drug resistance (Sophia and Lima, 2018; Andersson and Hughes, 2012; Merlin et al., 2011). Modified graphene has also been tested as gatekeepers for several chiral molecules, many of them with bioactive and toxic properties (Hauser et al., 2014). Among the advantages of employing functionalization processes on graphene and graphene oxide nanosheets, it can be cited: increase of sorbent selectivity towards specific classes of pollutants (Lazarevic-Pasti et al., 2018; Shrivas et al., 2017); outstanding adsorption performance in terms of capacity and high recoverability (Suo et al. 2018; Nodeh et al., 2015; Zhao and Liu, 2014); unlimited possibilities of functionalization, oftentimes by using the same reactant (Wanjeri et al., 2018; Bueno et al., 2017); some non-covalent functionalization can be reversed by non-aggressive methods (McCoy et al. 2015); functionalization routes can be developed by using bio and ecofriendly compounds, such as amino acids, wood extracts, chitosan, etc. (Cobos et al., 2018; Xue et al., 2018; Wang et al., 2017b; Wang et al., 2016b). Therefore, some disadvantages can also be pinpointed: high investment and syntheses cost, specific reactants may be needed to perform functionalization and certain operational conditions necessary, increasing the consumption of energy and other resources (Mahmoud et al., 2018); extensive reaction time is pointed out by some articles as a considerable obstacle in chemical functionalization, which increases its costs (Sainsbury et al., 2016); covalent functionalization generally is physically irreversible, hence reactants and graphene structures becomes irrecoverable (Feng et al., 2013); despite graphene itself being reported as non-toxic by some works (Lazarevic-Pasti et al., 2018; Mahmoud et al., 2018), functionalized graphene may releases byproducts in the form of gases and ionic species during its synthesis reaction and washing; since their toxicity and harm to human health are not yet entirely known, their disposal in the environment may be treated as a liability (Yang et al., 2013a; Hu and Zhou, 2013); some functionalized graphenes are rather difficult to separate after the adsorptive process, requiring elevated energy consumption and complex operations, such as centrifugation, nanofiltration, decantation and precipitation in large tanks, which demands elevated costs of assembly, operation and maintenance (Yao et al., 2017; Zou et al. 2016a), depending on the adsorption nature.

This paper has the objective to provide a critical review of the state of art referring to recent research works with functionalized graphene used as adsorbents of a wide class of organic pollutants. The environmental impacts of these pollutants, as well as the benefits of the treatment techniques employed have been widely explored.

\section{GRAPHENE AND ITS DERIVATIVES OVER HISTORY}

The first physical method by which single sheets of graphene were obtained with a certain degree of purity was developed by Novoselov et al. (2004), in which a Scotch-type tape was used to separate the graphene layers from graphite crystals by mechanical exfoliation. In the authors' words: 'Graphene is the name given to a single layer of carbon atoms densely packed into a benzene-ring structure". This discovery guaranteed him the Nobel Prize in 2010. As a consequence of this breakthrough research, the classical methods of obtaining graphene and GO have been improved through the use of new routes such as oxidation, chemical reduction, electrochemical deposition, ultrasonic exfoliation, among others (De Silva et al., 2017; Yusuf et al., 2015).

Brodie (1980), Staudenmaier (1898), and Hummers and Offeman (1958) were pioneers in developing efficient chemical routes to oxidize graphite. The most widespread method was Hummers', which consists of a strong oxidative attack on the $\mathrm{sp}^{2}$ carbons present in the structural plane by sulfuric acid and potassium permanganate (Figure 1a), followed by a finishing reaction with hydrogen peroxide (Hummers and 


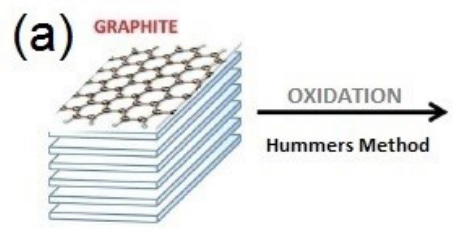

(c) Covalent Functionalization

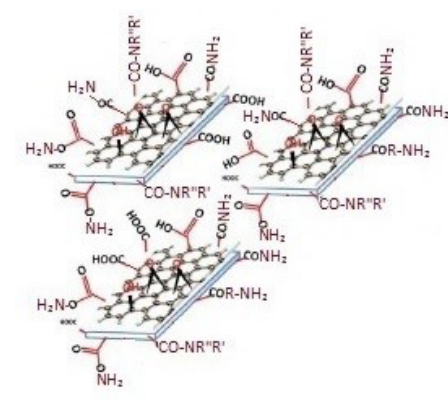

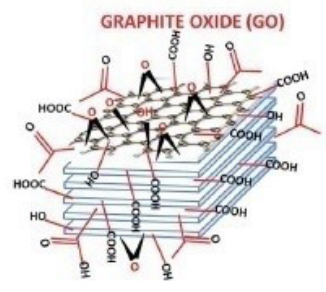

(d) Non-covalent functionalization
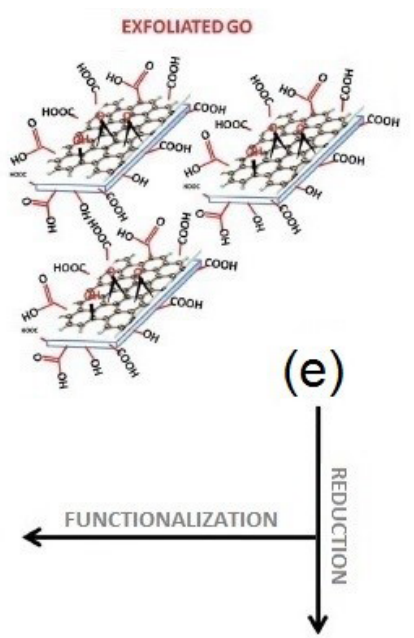

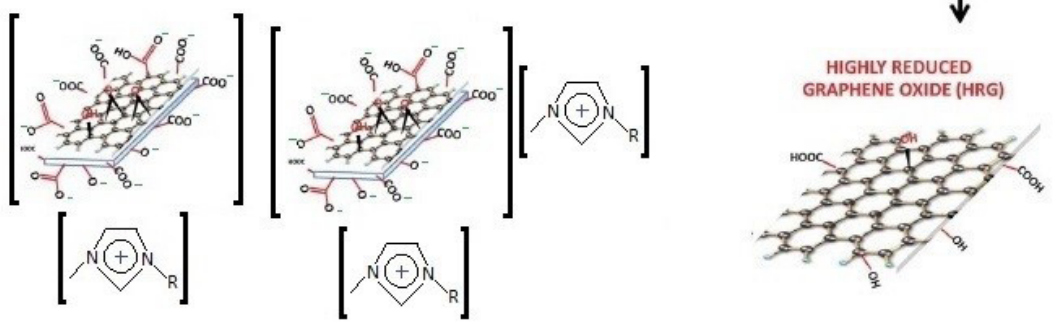

Figure 1. Schematic representation of the chemical route to oxidize, reduce and functionalize graphene.

Offeman, 1958). Over the years, Hummers' method has been optimized by the changing some variables, such as reaction time, process temperature, reactant nature and dosages (Muzyka et al., 2017). Nowadays, these synthetic procedures are named "modified Hummers' method"; however, they keep the original Hummers' method core steps. The exfoliation of graphite oxide is the next step to obtain pure and single layered graphene oxide (GO) (Figure 1b). These material properties are efficiently achieved by a sonication process (VelascoSotto et al., 2015; Pan and Aksay, 2011; Dreyer et al., 2010); however, other techniques, such as thermal exfoliation (You et al., 2013; Brodie, 1860) and the innovative directional freezing (Ogino et al., 2014) have been undertaken to obtain sonication-free GO nanosheets.

Following the exfoliation of GO, the materials can be modified according to their final application. In this sense, graphene-based nanomaterials have been widely used in several fields of the knowledge. One of these stages is the reduction of GO; reduced graphene oxides (r-GO) (Figure 1e) can be obtained by thermal reduction, through heating GO samples to temperatures varying from $250^{\circ} \mathrm{C}$ (Lavin-Lopez et al., 2017) to above $800^{\circ} \mathrm{C}$ (McAllister et al., 2007). Besides, a chemical reduction of GO can be achieved by adding reducing agents, whose choice depends mainly on avoiding parallel reactions, the cost of synthesis and also the aggressiveness of these compounds to the environment (De Silva et al., 2017). Hydrazine hydrate and dimethylhydrazine (Stankovich et al., 2006; Kovtyukhova et al., 1999) are the most used chemical reductants for GO; however, many ecofriendly substances have been researched to achieve this goal. Among these agents, it is possible to find ascorbic acid (Cobos et al., 2018; Begum et al., 2017; Ahmed et al., 2016), amino acids (Wang et al., 2017c; Ma et al., 2013a), proteins (Sheng et al., 2013; Liu et al., 2010) and microorganisms (Chouhan et al., 2016; Gurunathan et al., 2013; Akhavan and Ghaderi, 2012) reported in the literature.

\section{FUNCTIONALIZATION OF GRAPHENE AND ITS DERIVATIVES}

The covalent functionalization of graphene (Figure 1c) is characterized by the presence of functional groups bound to the basal plane structure by intense intermolecular forces, with high binding energy. This is typical of covalent bonds, which usually change the $\mathrm{sp}^{2}$ hybridization of its $\mathrm{G}$ networks, resulting in the formation of defects and loss of electronic properties (Vecera et al., 2017). Doubtless, the most common type of functionalization is the introduction of oxygencontaining groups on the nanosheet surface and it happens in graphite oxidation, with the formation of $\mathrm{COO}, \mathrm{COOH}, \mathrm{CO}$ and $\mathrm{OH}$ moieties (Wang et al., 2017d). Organic covalent functionalization reactions of graphene include two general routes: (a) the formation of covalent bonds between free radicals or dienophiles and $\mathrm{C}=\mathrm{C}$ bonds of pristine graphene and (b) the formation of covalent bonds between organic functional groups and the oxygen groups of GO (Georgakilas et al., 2012). Characteristic of these 
processes are the presence of carbonyl, hydroxyl and carboxyl groups (resulting from the oxidation of graphite itself by the Hummers method); nevertheless, functional moieties, such as amines (Wanjeri et al., 2018; Bueno et al., 2017), amides (Ahmed and Kim, 2017; Mrlík et al., 2016), nitro (Begum et al., 2017), thio-compounds (Mahmoodi et al., 2017; Cai and Larese-Casanova, 2016), carbene cycloaddition (Zan, 2014), among others, can be chemically added to the carbon plane edges and surface. Within the covalent routes, a functionalizing group, such as thionyl, can replace the hydroxyl groups that form on the graphene surface after oxidation (Cai and Larese-Casanova, 2016). The covalent bonding of dibromocarbene groups results in the re-hybridization of the carbon atoms through the formation of cyclopropyl groups, whose degree of defect in the covalent functional group can be confirmed by the Raman spectroscopy after the functionalization of graphene through carbene (Sainsbury et al., 2016).

Graphene or GO can also be functionalized through non-covalent routes, which involve the presence of functional moieties based on weak interactions between them and the structure of the graphene, such as $\pi-\pi$ stacking interactions, van der Waals forces and electrostatic interactions (Eigler and Hirsch, 2014). Generally, ionic, metallic or organometallic compounds such as $\mathrm{Al}^{3+}, \mathrm{Mn}^{2+}, \mathrm{CuO}_{2}^{2-}, \mathrm{Fe}_{3} \mathrm{O}_{4}$, $\mathrm{MnFe}_{3} \mathrm{O}_{4}{ }^{2+}$ (Bisht et al., 2017; Zheng et al., 2016; Muralikrishna et al., 2015), ionic and poly-ionic liquids, such as polyvinylimidazole, polyvinylpyrrolidone, triphenylenes, pyrene derivatives, among others are employed in non-covalent functionalization synthesis (Cai et al., 2016; Tamilarasan and Ramaprabhu, 2015; Parviz et al., 2012). Ionic (IL) and polymerized ionic liquids (PIL), such as imidazolium (Figure 1d) and vinylimidazolium, confer versatility to graphenederived nanomaterials, enhancing their adsorption capacity for gaseous pollutants, such as $\mathrm{CO}, \mathrm{CO}_{2}$, $\mathrm{NO}_{2}$ and $\mathrm{SO}_{2}$. According to Wang and Wang (2016) and Plechkova and Seddon (2008), although several chemical and physical properties of ILs and PILs have yet to be discovered, these ionic species possess distinct properties, including negligible volatility, high stability, high ionic conductivity, high polarity, and good solubility. Hence, they have been applied to carbon engineered nanocomposites, in innovative synthesis processes, and used as $\mathrm{CO}_{2}$ blockers with elevated capacity of capture in the form of photocatalysts, mixed-matrix membranes (MMMs), bubble column additives, gaseous adsorbents, among others (Sarfraz and Ba-Shammakh, 2018; Tamilarasan and Ramaprabhu, 2015). Organic polymeric compounds are also applied in both covalent and noncovalent functionalization; though it depends on the strength and nature of their bonds to the graphene basal planes (Xiang et al., 2016; Yang et al., 2013b).

\section{FUNCTIONALIZED GRAPHENE, ITS INTERACTIONS AND CHARACTERIZATION}

Graphene oxidenaturally has hydrophilic properties, physically showing colloidal suspension (Saleem et al., 2018); graphene, on the other hand, shows hydrophobicity, hence easily forms agglomerates irreversibly or even restacks to form graphite via van der Waals interactions in aqueous solutions (Ren et al., 2018; Petosa et al., 2010). The capacity of graphene derivatives to form $\pi-\pi$ interactions with adsorbate molecules deserves special attention, which depends on some factors: the occurrence of $\pi$ electrons in the two interacting species, their molecular geometry and the level of covalent functionalization, from which the graphene $\pi$ structure retention derives (Bottari et al., 2017; Georgakilas et al., 2012). In this sense, the presence of aromatic rings in the adsorbate molecule contributes highly to $\pi-\pi$ interactions with graphenebased adsorbents. Hydrogen bonds and electrostatic interactions are the dominant heteroaggregation mechanism of GO with layered double hydroxides and oxides, such as $\mathrm{TiO}_{2}, \mathrm{MgO}, \mathrm{ZnO}$, and positively charged mineral clays (Wang et al., 2017e; Wang et al., 2016a; Zou et al., 2016b). Moreover, electrostatic interactions govern the adsorption of ionic species, such as metals and some small dyes, which frequently are used in their ionized form. Meanwhile, the presence of $\mathrm{OH}, \mathrm{COOH}$ functional groups on the GO surface can enhance $\mathrm{H}$-bonds and van der Waals forces, which are reported in the adsorption of nitrogen and chlorinated species, such as pesticides and pharmaceuticals. In order to evaluate quantitative information of the nature of the interactions between the adsorbent and the adsorbate, many authors have applied Density Functional Theory (DFT), which allows the determination of significant parameters in the main interactions, such as activation energy, enthalpy of adsorption and intermolecular distances ( $\mathrm{Li}$ et al., 2017; Zou et al., 2016b). This has been possible through mathematical modeling and phenomenological simulations, performed by molecular dynamics software, such as Gaussian 09 and ORCA 3.3 (Im et al., 2017). Larijani et al. (2015) verified that non-covalent interactions (van der Waals forces) were present in order to stabilize the amino acid-graphene configuration in aqueous medium, information based in theoretical adsorption energies, calculated as $-4.8 \mathrm{kcal} / \mathrm{mol}$.

Characterization techniques must be thoroughly chosen according to the functionalized graphene application and desired properties; nevertheless, they consist of a key step in the research of nanocarbon materials as adsorbents. The most used nowadays are Fourrier-transform infrared spectroscopy (FTIR), X-ray photoelectronic spectroscopy (XPS), $\mathrm{X}$-ray diffraction (XRD), Raman spectroscopy, 
magnetization and transmission electronic microscopy (TEM). The presence of functional groups linked to the graphene structure is easily detected by FTIR (Figure 2a) and XPS, where new peaks appear at different frequencies $\left(\mathrm{cm}^{-1}\right)$ compared to the previous spectrum (graphene or GO before functionalization). As an example, Figure 2a shows the infrared spectra of the GO before and after functionalization with magnetite and silica. Moreover, the oxidation of graphite and further functionalization increases its interlayer space as a consequence of the carbon plane re-hybridization (Eigler and Hirsch, 2014). Such changes in graphite morphology are detected through electron transmission microscopy (TEM), combined with other analyses, XRD and Raman spectroscopy, and are responsible for facilitating the diffusion of the adsorbate molecules between the adsorbent layers, or even increasing the availability of active sites of this adsorbent. According to Yusuf et al. (2015), TEM is a powerful tool by which high resolution images can be obtained and generates numerous statistical data that make it possible to calculate the thickness between layers. Several data found in the literature evidence that graphene functionalization tends to introduce defects into graphene, such as vacancies and dislocations; however, defect-free structures can be found, especially in non-covalent functionalized graphene (Wu et al., 2018; Tkalya et al., 2014; Becerril et al, 2008). Magnetization techniques can be used to reveal the saturation point of the ferromagnetism and if the functionalized graphene shows diamagnetism or paramagnetism characteristics, which is important if the graphene is functionalized with magnetic nanoparticles, such as $\alpha-\mathrm{Fe}_{2} \mathrm{O}_{3}, \mathrm{Fe}_{3} \mathrm{O}_{4}, \mathrm{Mg}-\mathrm{Fe}_{2} \mathrm{O}_{4}$, among others (Liu et al., 2013; Ai et al., 2011). Finally, Atomic Force Microscopy (AFM) is another technique commonly used to unravel significant morphological characteristics of graphene-derived nanomaterials (Figure 2e-f). By AFM, graphene layer thickness, the number of graphene layers and the space between these layers can be determined. Moreover, some defects resulting from functionalization are clearly observed, and measured by AFM technique, which can give important data to describe surface phenomena. Wrinkles, folds and layers stacking might be indicative of interactions between functional groups over different graphene layers. Wrinkles can also be consequence of fast "explosion" that the GO is submitted to during reduction or even aggregation of two or more nanosheets (Ghislandi et al. 2015). Thicknesses were between 1 and $3 \mathrm{~nm}$ for more than $90 \%$ of chemically reduced graphene oxide (ChemrGO), according to the authors. Moreover, unremoved functional groups, or surfactants on Chem-rGO treated
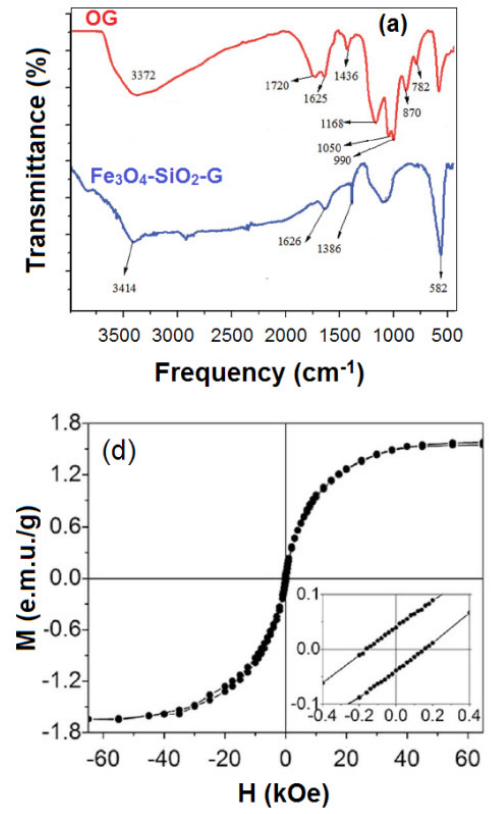
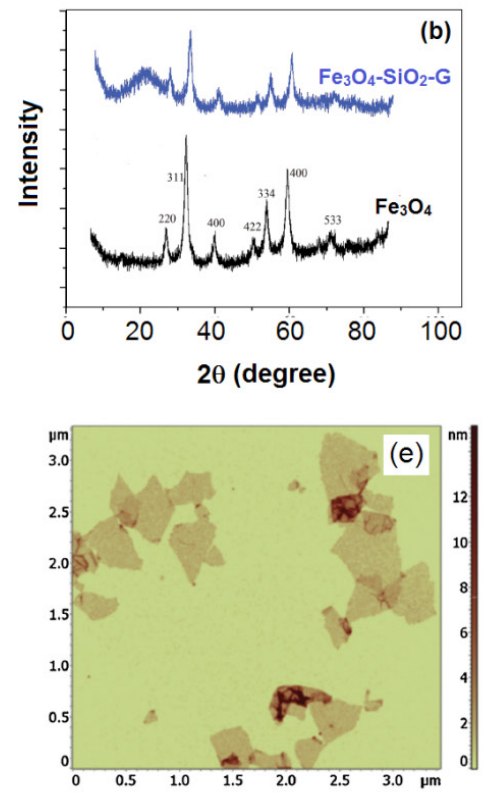
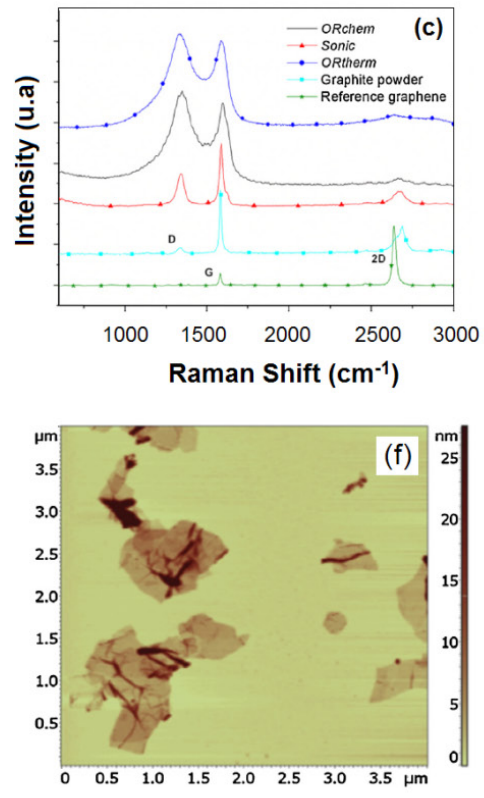

Figure 2: a) FTIR spectra for $\mathrm{GO}, \mathrm{Fe}_{3} \mathrm{O}_{4}-\mathrm{SiO}_{2}$ and $\mathrm{Fe}_{3} \mathrm{O}_{4}-\mathrm{SiO}_{2}$-Graphene (adapted from Nodeh et al., 2015, with permission from the Royal Society of Chemistry, Copyright 2015); b) XRD patterns of GO, $\mathrm{Fe}_{3} \mathrm{O}_{4}-\mathrm{SiO}_{2}$ and $\mathrm{Fe}_{3} \mathrm{O}_{4}-$ $\mathrm{SiO}_{2}$-Graphene (adapted from Nodeh et al., 2015, with permission from the Royal Society of Chemistry, Copyright $2015)$; c) Raman spectra of three engineering graphenes in comparison to graphite and graphene oxide (reproduced from Ghislandi et al., 2015, with permission from Elsevier, Copyright 2015); d) magnetic hysteresis loops of N-doped graphene (reproduced from Liu et al., 2013, with permission from Springer Nature, Copyright 2013); AFM topography for: e) exfoliated tapping mode of graphene; f) chemically oxidized/reduced graphene oxide, ChemrGO (reproduced from Ghislandi et al., 2015, with permission from Elsevier, Copyright 2015). 
surfaces can be easily detect by AFM technique through the appearance of roughness and wrinkles. Nanoparticles anchoring on graphene plane, such as magnetic $\alpha-\mathrm{Fe}_{3} \mathrm{O}_{4}, \mathrm{Fe}_{3} \mathrm{O}_{4}, \mathrm{MgO}, \mathrm{SiO}_{2}$, among others, are also detected by AFM topographies; particles with very different heights and sizes can be observed and measured through AFM images (Muñoz et al., 2018).

\section{ADSORPTION OF WATER POLLUTANTS}

Several works reported in the literature, which have explored the use of graphene based nanomaterials as adsorbent of water pollutants, have highlighted that functionalization increased their adsorption efficiency in comparison to their predecessors (Wu et al., 2016; Shi and Ye, 2015). Another remarkable characteristic of functionalized graphenes in comparison to GO is their elevated recyclability, which allows their reuse even after more than ten adsorption-desorption cycles (Wanjeri et al., 2018; Nodeh et al., 2015) as summarized in Table 1. However, the functionalization route must be carefully chosen according to the newdeveloped adsorbent and adsorbate properties, as well as the operating conditions of the adsorptive process. Furthermore, functionalization gives the graphene a high specificity, which can make it limited when used for different types of adsorbates.

Recent works have reported that GO and aggregated graphene may cause severe and continuous injury to the lungs after direct inhalation and ingestion, leading to inflammation of pulmonary cells, edema and granuloma formation, among other pathologies (Li et al., 2017; Wang et al., 2017d; Yusuf et al., 2015). GO is also reported as be toxic to bacteria and mammalian cells (Li et al., 2015); therefore, more in depth studies are needed to reach conclusions about the damages caused by functionalized graphene and graphene oxide on human and animals health.

Despite the reported advantages, one key point to be thoroughly considered when working with functionalized graphene as adsorbent is their difficulty of separation. It becomes a major challenge when it comes to operating on large scale. Nanofiltration with filters of Teflon or PTFE, vacuum filtration and centrifugation are employed nowadays to separate graphene-derived nanomaterials from aqueous media, however, this increases operational costs. Therefore, coagulation agents, such as $\mathrm{ZnO}$ and $\mathrm{MgO}$, should be employed after adsorption in order to ease its separation from adsorbate and minimize graphene's adverse influences on the environmental balance after its release (Wang et al., 2017d; Yao et al. 2017). On the other hand, many researchers have applied magnetic nanoparticles successfully to the graphene basal plane via non-covalent functionalization (Shi and Ye, 2015) as an alternative for aggregation and ultracoagulation, processes which add new chemicals after pollutant removal. Magnetite nanoparticles $\left(\mathrm{Fe}_{3} \mathrm{O}_{4}\right)$ are the most preferred due to their facility, low cost of production and large availability of $\mathrm{FeCl}_{3}$. Magnetite nanoparticles, such as $\mathrm{Fe}_{3} \mathrm{O}_{4}$ or $\alpha-\mathrm{Fe}_{2} \mathrm{O}_{3}$, are reported to be responsible for confering ferromagnetic properties to functionalized graphene nanosheets (Cai et al., 2016; Liu et al., 2013), leading to an easy recovery of the adsorbent after the incidence of a magnetic field on the solution by external magnets (Boruah et al., 2017). However, the energy costs of this application must be carefully analyzed to compare its viability with other separation process.

\section{Aromatic organic pollutants}

Aromatic compounds are the major part of the research involving organic pollutants; hence, their removal processes are particularly benefited by adsorption onto functionalized graphene or reduced graphene oxide, due to their very large delocalized $\pi$-electron systems, which provides strong $\pi-\pi$ stacking interaction with the aromatic rings of organic compounds (Yang, 2003; Dreyer et al., 2010; Zhu et al., 2010).

Paul et al. (2016) proposed a one-pot hydrothermal synthesis of a composite of $\mathrm{Ag} / \mathrm{Fe}_{2} \mathrm{O}_{3}$ anchored on reduced graphene oxide $\left(\mathrm{Ag} / \alpha-\mathrm{Fe}_{2} \mathrm{O}_{3}-\mathrm{rGO}\right)$ via homogeneous chemical precipitation of $\mathrm{Fe}(\mathrm{OH})_{3}$ and simultaneous reduction of $\operatorname{Ag}(\mathrm{I})$. The adsorbent was used to remove nitroarenes from aqueous solution. The Raman spectra of $\mathrm{Ag} / \alpha-\mathrm{Fe}_{2} \mathrm{O}_{3}-\mathrm{rGO}$ showed two characteristic peaks of $\mathrm{rGO}$, at 1352 and $1590 \mathrm{~cm}^{-1}$, corresponding to the D and $\mathrm{G}$ band; BET analysis showed high specific surface area and pore volume, of $772.65 \mathrm{~m}^{2} \cdot \mathrm{g}^{-1}$ and $1.47 \mathrm{~cm}^{3} \cdot \mathrm{g}^{-1}$, respectively; VSM analysis showed that the saturation magnetization of $\mathrm{Ag} / \alpha-\mathrm{Fe}_{2} \mathrm{O}_{3}-\mathrm{rGO}$ catalyst is $57.2 \mathrm{emu} \cdot \mathrm{g}^{-1}$. The synthesized $\mathrm{Ag} / \mathrm{Fe}_{2} \mathrm{O}_{3}$-rGO nanocomposite was used as magnetically recoverable sorbent for roomtemperature chemioselective reduction of aromatic nitro groups to the corresponding amines. The adsorbent was tested with 10 species of nitroarenes and the average yield and time of reaction evaluated were $95.9 \%$ and $41.5 \mathrm{~min}$ respectively; the $\mathrm{Ag} / \alpha$ $\mathrm{Fe}_{2} \mathrm{O}_{3}$-rGO showed selectivity higher than $99 \%$ with all nitroarene species.

Chavez-Sumarriva et al. (2016) employed reduced graphene oxide (r-GO) to remove dodecylbenzene sulfonate from aqueous solution at the optimum conditions of temperature, $25^{\circ} \mathrm{C}$, and contact time. A satisfactory adsorption capacity of $546.90 \mathrm{mg} \cdot \mathrm{g}^{-1}$ was achieved; however, kinetic data showed that the system reached the equilibrium state after a long time $(30 \mathrm{~h})$, with initial concentration of $700 \mathrm{mg} \cdot \mathrm{L}^{-1}$. The pseudo-second-order model fitted the kinetic data better, and the Langmuir isotherm is the one which best 
represented the adsorption. Moreover, hydrophobic interactions, hydrogen bonding, and $\pi-\pi$ interactions were pointed out by the authors as being the most representative according to a study of the $\mathrm{pH}$ influence on the adsorptive process.

Another type of metal-graphene oxide functionalization was synthesized by Shi and Ye (2015) to adsorb sulfonamides from environmental water body samples. The functionalization of $\mathrm{GO}$ was performed at mild temperature $\left(70^{\circ} \mathrm{C}\right)$ and anionic medium, under vigorous steering. The porphyrinfunctionalized $\mathrm{Fe}_{3} \mathrm{O}_{4}$-graphene oxide (TCPP-Fe $\mathrm{O}_{4}$ GO) nanocomposite was used in the adsorption of aromatic sulfanilamides, sulfaguanidine, sulfapyridine, sulfamethoxazole, sulfadiazine, sulfadimethoxine and sulfadimidine. TEM techniques can successfully depict the presence of metallic elements, such as aluminum, impregnated over graphene surfaces (Figure 3f). Such observation can be facilitated when a comparative basis between precursor, metal and functionalized graphene is established (Figure $3 \mathrm{~d}$ and e). Moreover, TEM images exhibited the presence of magnetic $\mathrm{Fe}_{3} \mathrm{O}_{4}$ nanoparticles in both $\mathrm{Fe}_{3} \mathrm{O}_{4}-\mathrm{GO}$ and TCPP- $\mathrm{Fe}_{3} \mathrm{O}_{4}-$
GO, and a disaggregation of these nanoparticles after the functionalization (Shi and Ye, 2015). However, the values of interlayer spaces before and after the TCPP addition are not presented in the work, which could give substantive information to explain the sulfonamide sorption mechanism. Adsorption results presented satisfactory water treatment efficiency and recovery, between the range $83.7 \%$ - $116.7 \%$ for sulfonamides in tap and river water samples. Moreover, the experiments showed an increase in the adsorption capacity of $\mathrm{Fe}_{3} \mathrm{O}_{4}-\mathrm{GO}$ after the functionalization with TCPP; the adsorption capacity increased from 115 to $190 \mathrm{mg} \cdot \mathrm{g}^{-1}$ for Sulfamethoxazole and from 184 to $272 \mathrm{mg} \cdot \mathrm{g}^{-1}$ for Sulfadimethoxine. The adsorption mechanism of the prepared TCPP-Fe $\mathrm{O}_{4}-\mathrm{GO}$ material was investigated and predicted through ionic chromatography, $\mathrm{pH}$ evaluation and charge balance on the adsorbent surface. The $\pi-\pi$ stacking and electrostatic attraction between the positively charged analytes and the negatively charged porphyrin-functionalized $\mathrm{Fe}_{3} \mathrm{O}_{4}$ GO accelerated the electron transfer between the materials. This is evidenced by the higher adsorption capacity obtained at acid $\mathrm{pH}$. (a)

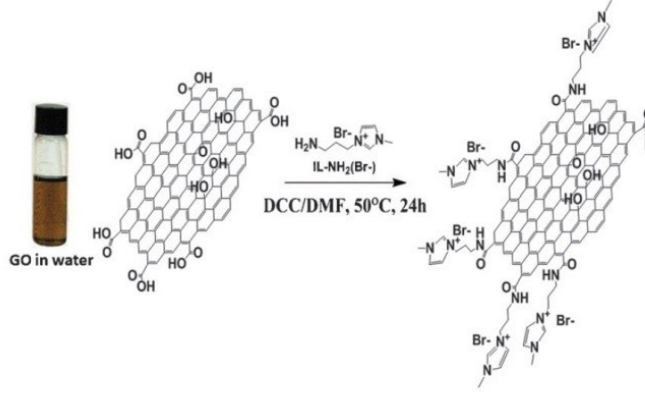

(b)

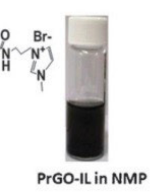

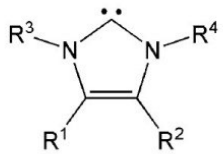

imidazolylidene NHCs

(c)
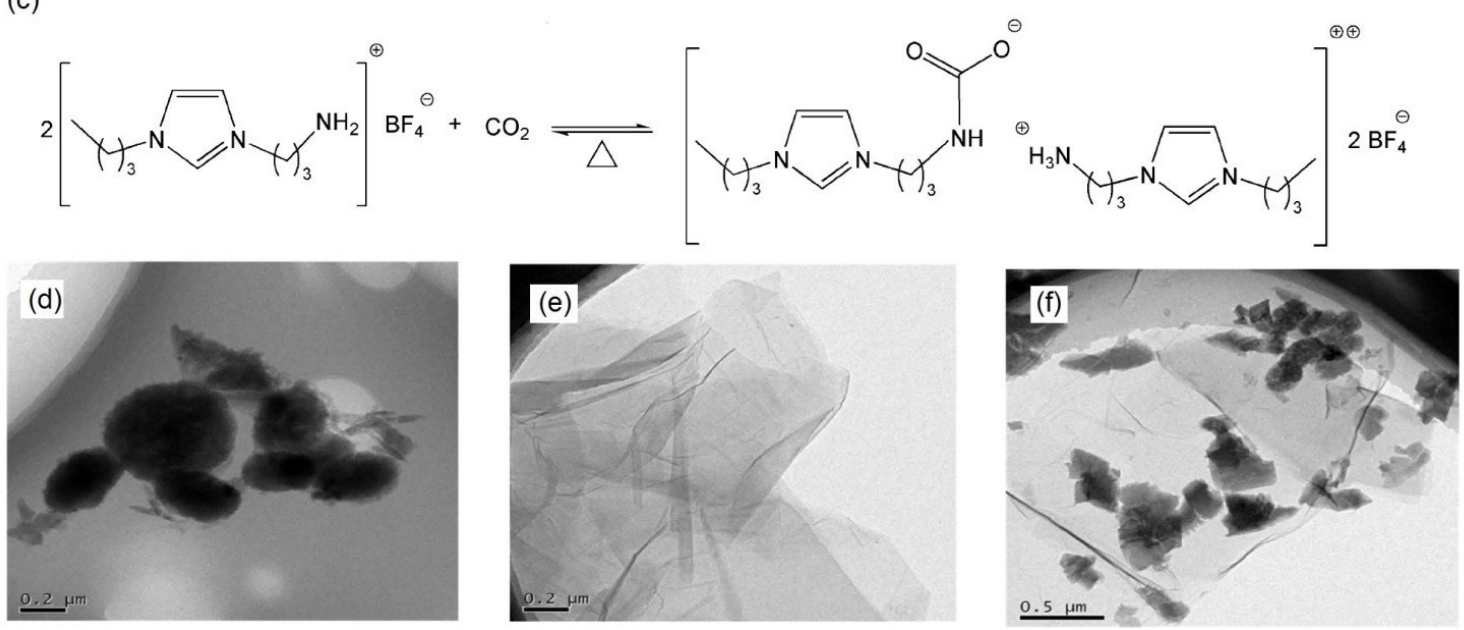

Figure 3. (a) Synthesis of partially reduced GO via PIL functionalization (PrGO-PIL) (reproduced from Bhunia et al. (2012), with permission from the Royal Society of Chemistry, Copyright 2018); (b) General structure of imidazolium ILs and imidazolylidene NHCs (reproduced from Wang and Wang (2016), with permission from John Wiley and Sons, Copyright 2018); (c) reaction between imidazolium amine-functionalized TSIL and CO, (reproduced from Wang and Wang (2016), with permission from John Wiley and Sons, Copyright 2018); TEM images for: (d) metallic aluminum framework; (e) reduced graphene oxide; (f) metallic aluminum-graphene oxide (MA-rGO) nanocomposite (reproduced from Wu et al. (2016), with permission from Springer Nature, Copyright 2018). 
Ionic liquid functionalized graphene and coated with magnetic nanoparticles have been successfully used as adsorbent for the extraction of polycyclic aromatic hydrocarbons (Pena et al., 2009). In that sense, magnetic poly-ionic liquid functionalized graphene (PGO-MILN) has been applied as adsorbent of chlorophenols by Cai et al. (2016). The magnetic solid-phase extraction (MSPE) technique was applied to extract chlorophenols from aqueous solution, with recoveries from 85.3 to $99.3 \%$. This result confirmed that PGO-MILN was a kind of highly effective MSPE material used to remove traces of chlorophenols in environmental water. Furthermore, tetrabromobisphenol A (TTBBA), an organic pollutant with capacity to promote the disruption of endocrine function, cytotoxicity and neurotoxicity, was submitted to adsorption by poly(tert-butyl acrylate)-GO (PtBAGO) (Zhao and Liu, 2014; Lilienthal et al., 2008). $\pi-\pi$ interactions were pointed out to be the dominant mechanism of the adsorption, due to the attraction forces generated between $\pi$-electrons in graphene $\mathrm{C}=\mathrm{C}$ bonds and benzene rings of the pollutant and the $\pi$-electrons on the basal plane of the adsorbent. Raman spectra showed that the $\mathrm{sp}^{2}$-hybridized carbon G-band (at $1583 \mathrm{~cm}^{-1}$ ) shifted to $1609 \mathrm{~cm}^{-1}$ after the adsorption, indicating that the adsorption occurred via $\pi-\pi$ stacking interactions between TBBPA and the aromatic structure on PtBA-GO (Ma et al., 2013b). $\pi$-electron bonds are detected in FTIR spectra, by the revelation of peaks at 1453 and $1369 \mathrm{~cm}^{-1}$, due to the symmetrical deformation vibration of the tertiary butyl groups in tert-butyl acrylate. In the studies of adsorption kinetics and equilibrium, performed by Zhao and Liu (2014), PtBA-GO presented maximum adsorption capacity of $54.17 \mathrm{mg} \cdot \mathrm{g}^{-1}$ at $293 \mathrm{~K}$, and the Freundlich model adjusted better to the experimental data $\left(\mathrm{R}^{2}, 0.9916\right)$. Moreover, the system reached the equilibrium state after $170 \mathrm{~min}$ and pseudo-secondorder was the most representative model for kinetic data $\left(\mathrm{R}^{2}, 0.9956\right)$. Desorption evaluation showed that PTBA-GO possesses an incredible potential of recyclability, since after six cycles, PtBA-GO adsorption capacity reduced $3.0 \%$. Bhunia et al. (2013) synthetized PIL-GO nanosheets through a simple reaction with 1-(3-aminopropyl)-3-methyl imidazolium bromide (IL-NH $\mathrm{N}_{2}\left(\mathrm{Br}^{-}\right)$) at homogeneous dispersion in polar aprotic organic solvents medium (Figure 3a). Moreover, this reaction took place at low temperatures $\left(50^{\circ} \mathrm{C}\right)$, which leads to a major cost saving in the process in comparison to many functionalization routes. Some of the most applied ionic liquids (ILs) are the imidazolium and the imidazolidene (Figure 3b), both compounds can be used to amine-functionalize ILs to enhance their capture properties towards $\mathrm{CO}_{2}$ (Figure 3c), as performed by Wang and Wang (2016). GO can be systematically functionalized by these
PILs and increase their sorption properties to adsorb metallic ions and also organic compounds (Cai et al. 2016).

\section{Aliphatic organic species}

Fe-Mn-thiol-functionalized graphene oxide (GO-Fe$\mathrm{Mn} / \mathrm{S})$ was applied to remove methylmercury $\left(\mathrm{CH}_{3} \mathrm{Hg}^{+}\right)$ from aqueous solution by Huang et al. (2017). In the adsorbent synthesis, 3-mercaptopropyltrimethoxysilane (3-MPTS) was used as a silanizing reagent after the electrochemical method to obtain GO-Fe-Mn. Three different precursor methods were used to sulphonate the composite: acetic acid method (SGO/Fe-Mn-ac), neutral method (SGO/Fe-Mn-ne), and ammonium hydroxide method (SGO/Fe-Mn-am) (Hakami et al., 2012; Gupta et al., 2014; He et al., 2012) and the maximum adsorption capacity was evaluated for the adsorbent obtained by each method. FTIR spectra revealed stretching vibrations at $673 \mathrm{~cm}^{-1}, 671 \mathrm{~cm}^{-1}$ and $679 \mathrm{~cm}^{-1}$, indicating the presence of a C-S bond in $\mathrm{SGO} / \mathrm{Fe}-\mathrm{Mn}-\mathrm{Ac}, \mathrm{SGO} / \mathrm{Fe}-\mathrm{Mn}-\mathrm{ne}$ and SGO/Fe-Mn-am, respectively; and stretching vibrations at $1043 \mathrm{~cm}^{-1}$, $1059 \mathrm{~cm}^{-1}$, and $1047 \mathrm{~cm}^{-1}$, corresponding to $\mathrm{C}-\mathrm{O} / \mathrm{Si}$ $\mathrm{O}-\mathrm{M}$, where $\mathrm{M}$ is $\mathrm{Si}, \mathrm{Fe}$, or $\mathrm{Mn}$ metal ligands. Raman spectra showed no changes in the spectra after the functionalization, indicating that there were no defect occurrences. Similar results were reported by Luo et al. (2017), when compared GO aerogel sponge and grafted GO-polyurethane composite (Figure 4b). XPS spectra revealed a peak at $282.9 \mathrm{eV}$, which corresponds to a $\mathrm{C}-\mathrm{Fe}$ bond, hence indicating that the Fe-functionalization had been successful. The BET surface area of SGO/Fe-Mnam was $2.79 \mathrm{~m}^{2} \cdot \mathrm{g}^{-1}$, noticeably smaller than 153.00 $\mathrm{m}^{2} \cdot \mathrm{g}^{-1}$ for $\mathrm{GO} / \mathrm{Fe}-\mathrm{Mn}$. However, the maximum surface area of GO in water is accessible only at concentrations below 35.00 $\mu \mathrm{g} \cdot \mathrm{mL}^{-1}$ (Eigler and Hirsch, 2014; Montes-Navajas et al., 2013). Accordingly, the specific surface area and pores distributions of functionalized graphene adsorbents are not a major factor influencing in the adsorption performance, yet the combination of structural properties of adsorbents and adsorbates defines the adsorption of organic species, such as organophosphorus pesticides, biomedical compounds and many classes of dyes (Lazarevic-Pasti et al., 2018; Yusuf et al., 2015; Kyzas et al., 2014). This is reflected in the adsorption parameters obtained: $33.36 \mathrm{mg} \cdot \mathrm{g}^{-}$ 1, $28.00 \mathrm{mg} \cdot \mathrm{g}^{-1}$ and $43.88 \mathrm{mg} \cdot \mathrm{g}^{-1}$ for $\mathrm{SGO} / \mathrm{Fe}-\mathrm{Mn}-\mathrm{ac}$, $\mathrm{SGO} / \mathrm{Fe}-\mathrm{Mn}$-ne and $\mathrm{SGO} / \mathrm{Fe}-\mathrm{Mn}$-am, respectively. It is clear that the differences in surface area between the three adsorbents did not influence their adsorption capacities. Kinetics studies showed that the uptake of all adsorbents reached the equilibrium state after $500 \mathrm{~min}$. The pseudo-second-order and Langmuir models fitted better the kinetic and equilibrium experimental data, respectively. The study suggested the potential viability of $\mathrm{SGO} / \mathrm{Fe}-\mathrm{Mn}$ for enhanced immobilization of $\mathrm{CH}_{3} \mathrm{Hg}^{+}$ 

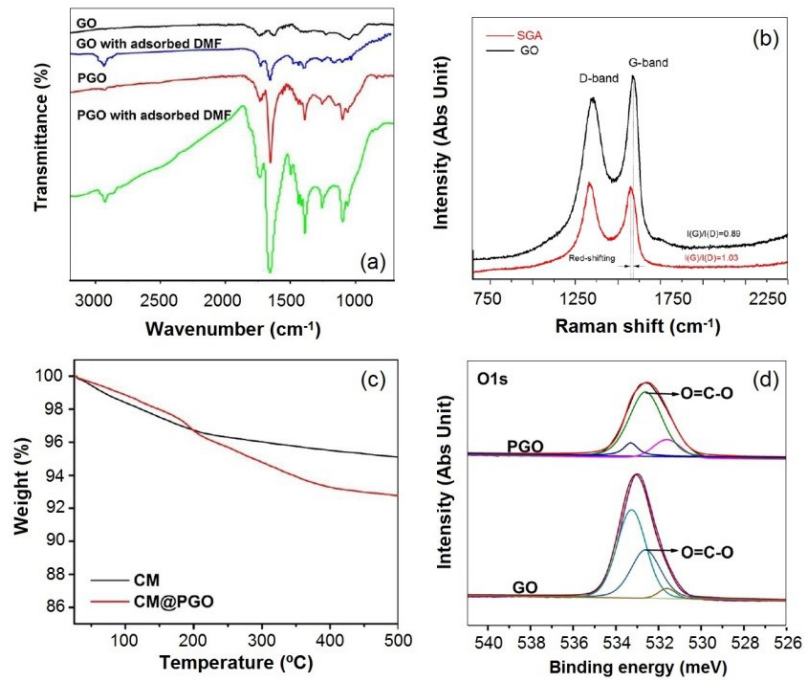

Figure 4. (a) FTIR spectra of GO, functionalized polyurethane-GO and for both samples after adsorption of aqueous organic wastes (reproduced from Fan et al. (2017), with permission from Springer Nature, Copyright 2018); (b) Raman spectra of GO aerogel and polyuretane-GO composite (reproduced from Luo et al. (2017), with permission from Springer Nature, Copyright 2018); (c) TGA analysis of copper-mesh and polymeric-GO (reproduced from Fan et al., 2017); (d) XPS spectra of GO and PGO (reproduced from Fan et al. (2017), with permission from Springer Nature, Copyright 2018).

in surface water, groundwater, and soil/sediments. The zeta potential evaluation revealed that the surface is negatively charged at each initial $\mathrm{pH}$ evaluated for the $\mathrm{S}-\mathrm{Fe}-\mathrm{Mn}-\mathrm{GO}$ suspension.

Aqueous organic waste disposal is a major concern when they are not correctly treated. These organic wastes have the potential to degrade into several compounds that can cause severe diseases in people who consume from this contaminated water body. To minimize the impact of organic matters, Fan et al. (2017) synthetized GO-anchored bio-functional polymer to remove N,N-dimethylformamide (DMF) from wastewater. FTIR spectra (Figure 4a) exhibited an intense peak at $1720 \mathrm{~cm}^{-1}$, which may be attributed to $\mathrm{C}=\mathrm{O}$ stretching vibration; moreover, increase of peaks at $1384 \mathrm{~cm}^{-1}$ indicated the strong bond of $\mathrm{O}=\mathrm{C}-\mathrm{O}$, which revealed that the polymers were grafted on GO successfully. XPS spectra of O1s (Figure 4d) revealed that the intensity of the peak at $533 \mathrm{eV}$, attributed to $\mathrm{O}=\mathrm{C}-\mathrm{O}$, showed a significant increase after polymerization when compared with $\mathrm{GO}$, which is an indicative that copper-mesh polymer was successfully grafted on GO. TGA (Figure 4c) showed a slight decrease on GO-polymer mass at $190^{\circ} \mathrm{C}$, which might be an indicative of low degree of graphite oxidation. Thus, there is no satisfactory discussion by the authors on these analyses.

\section{Pesticides}

Pesticides are widely used in agriculture, livestock and pest control; moreover, they have also been used by ordinary people in household gardening and veterinary practice. Many pesticides have aromatic rings in their structure, which leads to carcinogenic diseases, neurotoxicity and other pathologies (Wanjeri et al., 2018). Moreover, organophosphorus pesticide toxicity lies in the fact that these substances are inhibitors of the enzymes acetylcholinesterase, which leads to nervous system malfunction (Lazarevic-Pasti et al., 2018; Heidari and Razmi, 2012). The current main techniques employed to treat pesticides are advanced oxidation and chemical-microbial degradation of the compound. Adsorption onto several different materials has also been used as an end of pipe treatment (Suo et al., 2018; Zheng et al., 2016) Many researchers nowadays have been studying the adsorption of pesticides by graphene-derived nanomaterials due to their selectiveness, versatility, strong mechanical and other key surface properties (Lazarevic-Pasti et al., 2018; Chinthakindi et al., 2015). Table 1 summarizes the results of several functionalized graphene and GO nanocomposites employed as adsorbent of different classes of pesticides and herbicides found in the literature. For most of the functionalized graphene-based materials evaluated in this work, applied as adsorbents of pesticides, their adsorption was fitted by the Langmuir model, which assumes that the adsorption occurs in specific sites located on the sorbent homogeneous surface (Ruthven, 1984). Freundlich model, on the other hand, is characteristic of a heterogeneous surface and is usually applied for intermediate concentration systems (Ray et al., 2017). The pseudo-second-order kinetic model (PSO), that provides a better correlation for systems over a long period (Ho and McKay, 1999), is the one which fit the adsorption kinetics in the major works evaluated, as shown in Table 1. High recyclability (average of 10 cycles) of graphene-based adsorbents is pointed out as an outstanding advantage, since they can be re-applied in the treatment process.

The adsorption of the toxic triazine pesticide Ametryn was studied by Zhang et al. (2015), who used cellulose-GO as adsorbent. The maximum sorption capacity obtained at $\mathrm{pH} 9.0$ and $298 \mathrm{~K}$ was $8.53 \mathrm{mg} \cdot \mathrm{g}^{-}$ 1; however, it is 7 times lower than that achieved by Boruah et al. (2017), who applied $\mathrm{Fe}_{3} \mathrm{O}_{4}-\mathrm{GO}$ in the adsorption of the same pesticide at $\mathrm{pH}$ 5.0. The electrostatic interactions provoked by the positively charge surface of the adsorbent, which was employed below the sorbent $\mathrm{pH}_{\mathrm{pZC}}$ (5.5), were responsible for its elevated efficiency. According to Zhang et al. (2015), the ionic charges govern the adsorption of Ametryn onto cellulose-GO; nevertheless, the point of zero charge analysis was not performed for this adsorbent. 
This lack of information leads to the assumption that interactions of different natures are involved in the adsorption mechanism.

Wanjeri et al. (2018) used the polymeric magnetic functionalized $\mathrm{GO}$ (2-PEA- $\mathrm{Fe}_{3} \mathrm{O}_{4}-\mathrm{GO}$ ) to remove three types of chlorinated pesticides, Chlorpyrifos, Parathion and Malathion. Excellent adsorption capacity was obtained for Parathion adsorption (135.00 $\left.\mathrm{mg} \cdot \mathrm{g}^{-1}\right)$; all experiments were conducted at pH 10 and environmental temperature. The isotherm which best fitted the adsorption for the three pesticides was the Sips model, although the Langmuir model also gave a good fitting. According to the data found in the literature, shown in Table 1, the adsorption fittings of Chlorpyrifos are contradictory; thus, there are experimental data better adjusted by Langmuir (Suo et al., 2018; Nodeh et al., 2015), Freundlich (LazarevicPasti et al., 2018) and Sips (Wanjeri et al., 2018) models.
The Sips model, as well as the combined LangmuirFreundlich, allow assessing empirically the degree of heterogeneity on the adsorbent active sites (Carvalho et al. 2012; Ho et al., 2002). According to Wanjeri et al. (2018), high heterogeneity was attributed to the various surface groups on the nanocomposite and hydrogen bonds and $\pi-\pi$ interactions between the carbon plane and the heteroatoms. Furthermore, according to some authors, the adsorption of Chlorpyrifos (Figure 5) is not affected by the solution $\mathrm{pH}$ (Lazarevic-Pasti et al., 2018; Maliyekkal et al., 2013), which lacks a more concise evaluation of the charged donor-receptor interactions on the adsorbent surface via point of zero charge and Zeta potential analyses.

\section{Bio and pharmacologic compounds}

Kyzas et al. (2015a) and most recently, Hiew et al. (2018) made a systematic and detailed overview

Table 1. Comparative study for adsorption of pesticides and organic compounds onto functionalized graphene derivatives.

\begin{tabular}{|c|c|c|c|c|c|c|c|c|c|}
\hline Adsorbent & $\begin{array}{c}\mathrm{S}_{\mathrm{BET}}, \\
\mathrm{cm}^{2} \cdot \mathbf{g}^{-1}\end{array}$ & Adsorbate & $\begin{array}{c}\text { Isotherm } \\
\text { model }\end{array}$ & $\begin{array}{c}\mathbf{q} \mathbf{m}, \\
\mathbf{m g} \cdot \mathbf{g}^{-1}\end{array}$ & $\begin{array}{c}\text { Eq. time, } \\
\text { min }\end{array}$ & $\begin{array}{l}\begin{array}{l}\text { Kinetic } \\
\text { model * }\end{array} \\
\end{array}$ & pH & $\begin{array}{l}\text { Reg. } \\
\text { cycles }\end{array}$ & Reference \\
\hline CM-P(GO) & - & DMF & Langmuir & 95.03 & 660 & PFO & - & 3 & $\begin{array}{c}\text { Fan et al. } \\
(2017) \\
\text { Lazarevic- }\end{array}$ \\
\hline GNP & - & Chlorpyrifos & Freundlich & 140 & 1440 & - & 6.0 & - & $\begin{array}{l}\text { Pasti et al., } \\
2018\end{array}$ \\
\hline 2-PEA-Fe $\mathrm{O}_{4}-\mathrm{GO}$ & 133.00 & Chlorpyrifos & Sips & 25.60 & 20 & PSO & 7.0 & 10 & $\begin{array}{l}\text { Wanjeri et } \\
\text { al. (2018) }\end{array}$ \\
\hline $\begin{array}{l}\text { corn straw } \\
\text { cellulose-GO }\end{array}$ & 160.37 & Chlorpyrifos & Langmuir & 120.48 & - & PSO & $\begin{array}{l}1.0- \\
7.0\end{array}$ & 8 & $\begin{array}{l}\text { Suo et al. } \\
\text { (2018) }\end{array}$ \\
\hline $\begin{array}{l}\mathrm{SiO}_{2}-\mathrm{Fe}_{3} \mathrm{O}_{4}- \\
\text { graphene }\end{array}$ & - & Chlorpyrifos & Langmuir & 16.58 & - & - & 6.5 & 15 & $\begin{array}{l}\text { Nodeh et al. } \\
\quad(2015)\end{array}$ \\
\hline$\beta-\mathrm{CD}-\mathrm{Fe}_{3} \mathrm{O}_{4}-\mathrm{GO}$ & 250.33 & Thiacloprid & Langmuir & 3.11 & 60 & PSO & - & - & $\begin{array}{l}\text { Liu et al. } \\
\text { (2017) }\end{array}$ \\
\hline$\beta-\mathrm{CD}-\mathrm{Fe}_{3} \mathrm{O}_{4}-\mathrm{GO}$ & 250.33 & Thiamethoxam & Freundlich & 0.66 & 60 & PSO & - & - & $\begin{array}{l}\text { Liu et al. } \\
\text { (2017) }\end{array}$ \\
\hline$\beta-\mathrm{CD}-\mathrm{Fe}_{3} \mathrm{O}_{4}-\mathrm{GO}$ & 250.33 & Imidacloprid & Freundlich & 1.42 & 60 & PSO & - & - & $\begin{array}{l}\text { Liu et al. } \\
\text { (2017) }\end{array}$ \\
\hline 2-PEA-Fe $\mathrm{O}_{4}-\mathrm{GO}$ & 133.00 & Parathion & Sips & 135.00 & 40 & PSO & 11.0 & 10 & $\begin{array}{l}\text { Wanjeri et } \\
\text { al. (2018) }\end{array}$ \\
\hline 2-PEA-Fe ${ }_{3} \mathrm{O}_{4}-\mathrm{GO}$ & 133.00 & Malathion & Sips & 61.90 & 20 & PSO & 3.0 & 10 & $\begin{array}{l}\text { Wanjeri et } \\
\text { al. (2018) }\end{array}$ \\
\hline $\mathrm{Fe}_{3} \mathrm{O}_{4}-\mathrm{r}-\mathrm{GO}$ & - & Ametryn & Langmuir & 60.90 & 70 & PSO & 5.0 & 7 & $\begin{array}{l}\text { Boruah et al. } \\
\quad(2017)\end{array}$ \\
\hline Cellulose-r-GO & - & Ametryn & Langmuir & 8.53 & - & - & 9.0 & 6 & $\begin{array}{l}\text { Zhang et al. } \\
\text { (2015) }\end{array}$ \\
\hline $\begin{array}{l}\mathrm{SiO}_{2}-\mathrm{Fe}_{3} \mathrm{O}_{4}- \\
\text { graphene }\end{array}$ & - & Lindane & Langmuir & 13.04 & - & - & 6.5 & 15 & $\begin{array}{l}\text { Nodeh et al. } \\
\quad(2015)\end{array}$ \\
\hline Ag-r-GO & 1123.0 & Lindane & - & 827.00 & 15 & - & $\begin{array}{l}3.0- \\
9.0\end{array}$ & 5 & $\begin{array}{l}\text { Gupta et al. } \\
\text { (2015) }\end{array}$ \\
\hline $\begin{array}{l}\mathrm{SiO}_{2}-\mathrm{Fe}_{3} \mathrm{O}_{4}- \\
\text { graphene }\end{array}$ & - & Hexaconazole & Langmuir & 18.69 & - & - & 6.5 & 15 & $\begin{array}{l}\text { Nodeh et al. } \\
\quad(2015)\end{array}$ \\
\hline $\begin{array}{l}\mathrm{SiO}_{2}-\mathrm{Fe}_{3} \mathrm{O}_{4}- \\
\text { graphene }\end{array}$ & - & Azaconazole & Langmuir & 15.35 & - & - & 6.5 & 15 & $\begin{array}{l}\text { Nodeh et al. } \\
\quad(2015)\end{array}$ \\
\hline $\mathrm{Fe}_{3} \mathrm{O}_{4}-\mathrm{GO}$ & - & Endrin & Langmuir & 99.00 & 30 & $\mathrm{PFO}$ & 4.0 & - & $\begin{array}{l}\text { Shrivas et al. } \\
\quad(2017)\end{array}$ \\
\hline $\mathrm{Fe}_{3} \mathrm{O}_{4}-\mathrm{GO}$ & - & Dieldrin & Langmuir & 1.00 & 30 & $\mathrm{PFO}$ & 4.0 & - & $\begin{array}{l}\text { Shrivas et al. } \\
\quad(2017)\end{array}$ \\
\hline $\begin{array}{l}\text { Graphene } \\
\text { quantum dots }\end{array}$ & 1221.0 & Oxamyl & Langmuir & 70.12 & 25 & PSO & 8.0 & - & $\begin{array}{l}\text { Agarwal et } \\
\text { al. (2016) }\end{array}$ \\
\hline
\end{tabular}




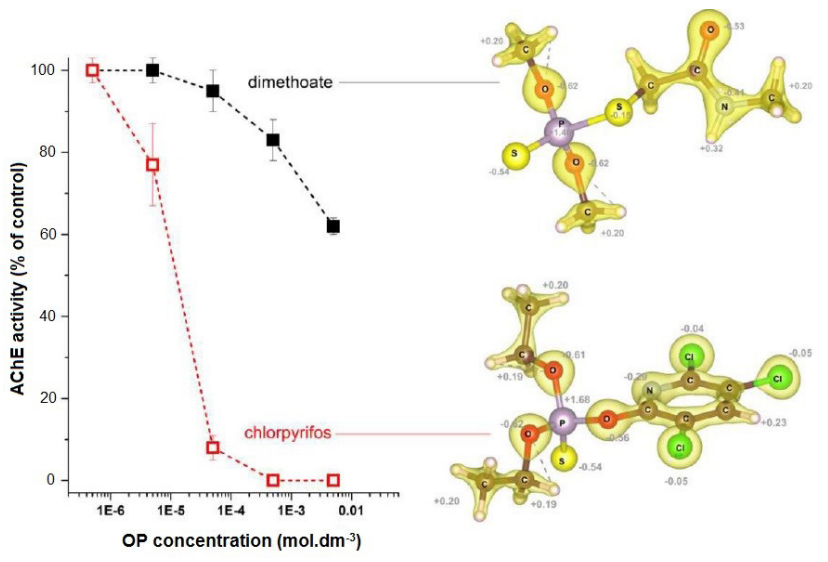

Figure 5. Adsorption of dimetholate and chlorpyrifos onto graphene oxide (reproduced from Lazarevic-Pasti et al. (2018), with permission from the Royal Society of Chemistry, Copyright 2018).

of several pharmaceutical compound treatments via adsorption, their increasing consumption by humans and animals, and the dangerous passive derived from the discharge of pharmaceutical active compounds in the environment. According to the data presented in the literature, about $30-90 \%$ of the pharmaceuticals remain undegradable in humans and animal bodies and are excreted as active compounds in the environment (Khan et al., 2017; Rivera-Utrilla et al., 2013).

Understanding the mechanisms of pharmaceutical adsorption onto graphene and GO is a key-step to optimize the adsorption. In this sense, Khan et al. (2017) evaluated different adsorbent-adsorbate interaction behaviors involving pharmaceuticals. Pharmacological compounds, such as levofloxacin (Sun et al. 2018; Dong et al., 2015), ciprofloxacin (Rostamian and Behnejad, 2018; Wang et al., 2016b; Fei et al., 2016; Ma et al., 2015), dorzolamide (Kyzas et al., 2014), tetracycline (Zhu et al., 2018; Lin et al., 2013; Ghadim et al., 2013), ibuprofen (Banerjee et al., 2016), paracetamol (Shan et al., 2017), aspirin (Akpotu and Moodley, 2018; AlKhateeb et al., 2014), amoxicillin (Kerkez-Kuyumcu et al. 2016), among others, have had their adsorption onto graphene-based nanomaterials evaluated in several studies reported in the literature, as shown in Table 2.

Different interaction natures between pharmaceuticals and GO are shown in Figure 6 and Figure $7 \mathrm{a}-\mathrm{d}$. $\pi-\pi$ interactions, hydrogen bonding and hydrophobic interactions are present in the mechanisms of several compounds. The abundance of $\pi$-electrons in the $\mathrm{G}$ and $\mathrm{GO}$ structures, together with large electron clouds due to the aromatic rings in the molecules of the pharmaceuticals, tends to favor $\pi-\pi$ interactions (Yu et al., 2015; Eigler and Hirsch, 2014). Moreover, there are plenty of research articles in the literature regarding the use of Density Functional Theory (DFT) to investigate the mechanisms and energetic aspects on the interaction between biomolecules and graphene-derived adsorbents, e.g., amino acids and GO. DOS curves and total density map showed that weak interactions occurred between delocalized $\pi$ electrons of aromatic rings and the lone-pair electrons of oxygen atoms, distributed on the GO surface. Noncovalent interactions are also detected by these tools, as a consequence of weak but numerous van der Waals forces between the molecules (Larijani et al., 2015). The addition of certain charged functional groups on the surface of the graphene basal plane can change the balance of charges, which tends to attract the ionic compounds of opposite charge via electrostatic attraction; such mechanism was observed by Cai and Larese-Casanova (2016), they evaluated the influence of $\mathrm{pH}$ on the adsorption of the cationic atenolol and the anionic ibuprofen by ethylenediamine functionalized GO. In that sense, the adsorption of pharmaceuticals is favored by a cationic attraction when the $\mathrm{pK}_{\mathrm{a}}$ is higher than the solution $\mathrm{pH}$, as depicted in Figure 6; the opposite phenomenon drives the adsorption via anionic attraction (Khan et al., 2017). Hydrogen bonds, weak interactions that form between a hydrogen with a partial positive charge and a more electronegative atom such as oxygen, fluorine or chlorine, can be formed between the hydrogen atoms present in the functional moieties and the partially negative charged atoms of the adsorbate molecule. Moreover, an undesirable effect is generated when the molecules of water form hydrogen bonds with the oxygen electronic pair present in the $\mathrm{COOH}, \mathrm{OH}$ and $\mathrm{COC}$ groups. This tends to occupy the GO active sites, and consequently decrease the adsorption of tetracyclines (Khan et al., 2017). However, the adsorption of tetracycline onto graphene nanosheets is reported to be mainly governed by $\pi-\pi$ interactions (Yu et al., 2015)

Functionalized graphene has been studied as an adsorbent of pharmacologic-nature contaminants in wastewater, as proposed by Cai and Larese-Casanova (2016). Graphene oxide was functionalized with ethylenediamine (ED-GO) through an acyl chlorination and amidation process that gave a net positive surface charge at $\mathrm{pH}<8.1$. ED-G had greater sorption capacity for anionic ibuprofen compared to cationic atenolol and neutral carbamazepine. ED-GO XRD diffractograms present an enlargement of the characteristic graphite peak at $2 \theta=27^{\circ}$, besides the disappearance of the characteristic peak for $\mathrm{GO}$ at $2 \theta=8.5^{\circ}$, which is caused by the presence of oxygen functional groups between the layers (Cai and Larese-Casanova, 2016). FTIR spectra for ED-GO reveal the replacement of most O groups with $\mathrm{N}$ groups and confirms ethylenediamine functionalization, which is characterized by the following stretchings: $1168 \mathrm{~cm}^{-1}(\mathrm{C}-\mathrm{N}), 1560 \mathrm{~cm}^{-1}(\mathrm{~N}-$ $\mathrm{H})$ and $1678 \mathrm{~cm}^{-1}(\mathrm{~N}-\mathrm{C}=\mathrm{O})$ (Velickovic et al., 2013; Vukovic et al., 2010; Ramanathan et al., 2005). Ma et al. (2015) evaluated the adsorption of bisphenol-A (BPA) 
Table 2. Comparative study of the data found in the literature for adsorption of pharmacological compounds onto functionalized graphene.

\begin{tabular}{|c|c|c|c|c|c|c|c|c|}
\hline Adsorbent & $\begin{array}{l}\mathrm{S}_{\mathrm{BET}}, \\
\mathrm{cm}^{2} \cdot \mathrm{g}^{-1}\end{array}$ & Adsorbate & $\begin{array}{c}\text { Isotherm } \\
\text { model }\end{array}$ & $\begin{array}{c}\mathbf{q}_{\mathrm{m}}, \\
\mathrm{mg} \cdot \mathrm{g}^{-1}\end{array}$ & $\begin{array}{c}\text { Eq. time, } \\
\text { min }\end{array}$ & $\begin{array}{l}\text { Kinetic } \\
\text { model * }\end{array}$ & pH & Reference \\
\hline $\mathrm{GO}$ & 108.71 & Metformin & Freundlich & 96.75 & 40 & PSO & 6.0 & Zhu et al. (2017) \\
\hline$\beta$-CD-PL-graphene & 105.50 & $17-\beta$-estradiol & Langmuir & 85.80 & 480 & PSO & $\begin{array}{c}4.2- \\
5.1\end{array}$ & $\begin{array}{l}\text { Jiang et al. } \\
(2017 b)\end{array}$ \\
\hline DFB20-GO & 27.70 & Paracetamol & Freundlich & 0.10 & 2160 & - & $\begin{array}{l}6.0- \\
9.0\end{array}$ & $\begin{array}{l}\text { Shan et al. } \\
\text { (2017) }\end{array}$ \\
\hline Ethylenediamine-GO & 771.00 & Ibuprofen & Freundlich & 36.00 & 240 & PSO & $<4.0$ & $\begin{array}{l}\text { Cai and Larese- } \\
\text { Casanova (2016) }\end{array}$ \\
\hline GNP & - & Ibuprofen & Langmuir & 3.72 & 60 & PSO & 6.0 & $\begin{array}{l}\text { Banerjee et al. } \\
\text { (2016) }\end{array}$ \\
\hline Double-oxidized GO & 51.20 & Acetaminophen & Langmuir & 704.00 & 100 & PSO & $<8.0$ & $\begin{array}{l}\text { Moussavi et al. } \\
\text { (2016) }\end{array}$ \\
\hline $\mathrm{Fe}_{3} \mathrm{O}_{4}-\mathrm{GNP}$ & 543.20 & Amoxicillin & Temkin & 14.10 & 175 & PSO & $\begin{array}{l}3.0- \\
5.0\end{array}$ & $\begin{array}{c}\text { Kerkez- } \\
\text { Kuyumcu et al. } \\
(2016)\end{array}$ \\
\hline $\mathrm{Fe}_{3} \mathrm{O}_{4}-\mathrm{GO}$ & - & Tetracycline & Langmuir & 39.10 & 20 & PSO & $>5.0$ & Lin et al. (2013) \\
\hline $\mathrm{CH}_{4} \mathrm{~N}_{2} \mathrm{~S}-\mathrm{Fe}_{3} \mathrm{O}_{4}-\mathrm{GO}$ & - & Tetracycline & Langmuir & 1233.00 & 2000 & PSO & 4.0 & $\begin{array}{l}\text { Yang et al. } \\
\text { (2017) }\end{array}$ \\
\hline $\mathrm{Ca}^{2+}$ alginate-GO & - & Tetracycline & Freundlich & 131.57 & 780 & PSO & 6.0 & Zhu et al. (2018) \\
\hline $\begin{array}{l}\text { poly(acrylic acid)- } \\
\text { chitosan-GO }\end{array}$ & 3.00 & Dorzolamide & $\begin{array}{l}\text { Langmuir- } \\
\text { Freundlich }\end{array}$ & 175.00 & 1440 & PSO & 3.0 & $\begin{array}{l}\text { Kyzas et al. } \\
(2014)\end{array}$ \\
\hline $\mathrm{GO}$ & - & Ciprofloxacin & Langmuir & 409.00 & 120 & - & 7.0 & Sun et al. (2018) \\
\hline r-GO & 231.38 & Ciprofloxacin & Langmuir & 235.64 & 120 & PSO & 8.0 & Ma et al. (2015) \\
\hline $\mathrm{Fe}_{3} \mathrm{O}_{4}-\mathrm{r}-\mathrm{GO}$ & - & Ciprofloxacin & Langmuir & 18.22 & 700 & PSO & 6.5 & $\begin{array}{l}\text { Tang et al. } \\
\text { (2013) }\end{array}$ \\
\hline GO & - & Levofloxacin & Langmuir & 303.00 & 120 & - & 7.0 & Sun et al. (2018) \\
\hline $\mathrm{Fe}_{3} \mathrm{O}_{4}-\mathrm{r}-\mathrm{GO}$ & - & Norfloxacin & Temkin & 22.20 & 700 & PSO & 4.5 & $\begin{array}{l}\text { Tang et al. } \\
\text { (2013) }\end{array}$ \\
\hline GNP & 635.20 & Aspirin & - & 12.98 & 30 & PSO & 8.0 & $\begin{array}{l}\text { Al-Khateeb et } \\
\text { al. (2014) }\end{array}$ \\
\hline MCM-41-graphene & 50.90 & Aspirin & Freundlich & 769.20 & 200 & PSO & $\begin{array}{l}2.0- \\
4.0\end{array}$ & $\begin{array}{c}\text { Akpotu and } \\
\text { Moodley (2018) }\end{array}$ \\
\hline Single-layered-GO & - & Diclofenac & Langmuir & 500.00 & 360 & - & 11.0 & $\begin{array}{l}\text { Nam et al. } \\
\text { (2015) }\end{array}$ \\
\hline Single-layered-GO & - & $\begin{array}{c}\text { Sulfa- } \\
\text { methoxazole }\end{array}$ & Langmuir & 3709.00 & 360 & - & 11.0 & $\begin{array}{l}\text { Nam et al. } \\
\text { (2015) }\end{array}$ \\
\hline GO & - & Propanolol & $\begin{array}{l}\text { Langmuir- } \\
\text { Freundlich }\end{array}$ & 67.00 & 180 & PSO & 2.0 & $\begin{array}{l}\text { Kyzas et al. } \\
(2015 b)\end{array}$ \\
\hline GO & - & Atenolol & $\begin{array}{l}\text { Langmuir- } \\
\text { Freundlich }\end{array}$ & 116.00 & 180 & PSO & 2.0 & $\begin{array}{l}\text { Kyzas et al. } \\
(2015 b)\end{array}$ \\
\hline Graphene & 327.00 & Bisphenol-A & Langmuir & 182.00 & 360 & PSO & $\begin{array}{l}2.0- \\
6.0\end{array}$ & Xu et al. (2012) \\
\hline $\begin{array}{l}\beta \text {-cyclodextrin- } \mathrm{Fe}_{3} \mathrm{O}_{4}- \\
\text { graphene }\end{array}$ & - & Bisphenol-A & Langmuir & 59.60 & 240 & PSO & 6.0 & $\begin{array}{l}\text { Ragavan and } \\
\text { Rastogi (2017) }\end{array}$ \\
\hline
\end{tabular}

* For the kinetic models, PFO means pseudo-first-order; PSO, pseudo-second-order; and IPD, intraparticle diffusion.

onto graphene and found that many new peaks had been introduced in the FTIR spectrum of graphene after BPA adsorption (Figure $7 \mathrm{~b}$ ). These new peaks at 2800-3000 $\mathrm{cm}^{-1}$ and $400-1800 \mathrm{~cm}^{-1}$ are in accord with the peaks of the FTIR spectrum of BPA and appeared at significant intensities, which indicated that a large amount of BPA molecules had been adsorbed on the surface of graphene. A dual-compound adsorption process was performed to evaluate the effect of adsorbate-adsorbate interactions on each single compound adsorption efficiency; the presence of dual sorbates diminished the sorption extent for each compound compared to sorption in single sorbate experiments. The Freundlich isotherm model fitted better the adsorption of ibuprofen and other pharmaceutical pollutants onto ED-GO (Table 2). These results are in disagreement with other ibuprofen data reported in the literature (Banerjee et al., 2016), though they can be explained by the elevated BET surface area $\left(771 \mathrm{~m}^{2} \cdot \mathrm{g}^{-1}\right)$ of ED-GO in comparison to the other adsorbents, evidencing a greater availability of heterogeneous sites on ED-GO surface (Ruthven, 1984). Furthermore, the Freundlich constants $\left(K_{F}\right)$ obtained for ibuprofen, carbamazepine and atenolol were 291, 129 and 100, respectively.

The reported data for the adsorption of tetracycline by magnetite-GO showed an outstanding increase in the adsorption capacity by comparison to $\mathrm{Fe}_{3} \mathrm{O}_{4}-\mathrm{GO}$ (Lin et al., 2013) and thiourea-dioxide functionalized 


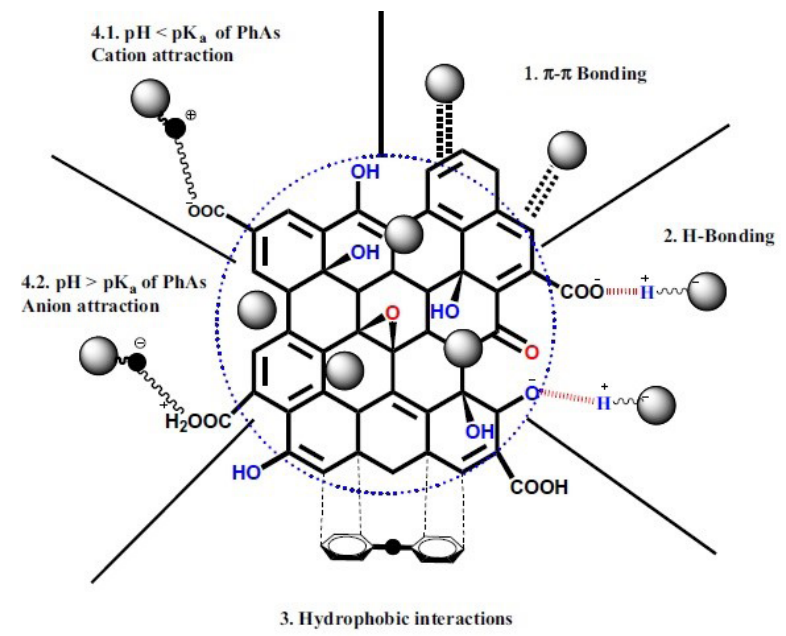

Figure 6. Different interactions between pharmaceutical compounds and GO. Reproduced from Khan et al. (2017), with permission from Springer Nature, Copyright 2018.

$\mathrm{GO}, \mathrm{CH}_{4} \mathrm{~N}_{2} \mathrm{~S}-\mathrm{Fe}_{3} \mathrm{O}_{4}-\mathrm{GO}$ (Jiang et al., 2017): 39.10 and $1233.00 \mathrm{mg} \cdot \mathrm{g}^{-1}$, respectively(Table 2$)$. Thiourea-dioxide increased the adsorptive properties of the magnetite-
GO through forming strong $\pi-\pi$ and hydrophobic interactions with the tetracycline molecule, as observed by the endothermic thermodynamic parameters $\left(\Delta \mathrm{H}^{\mathrm{o}}=\right.$ $\left.6.65 \mathrm{~kJ} \cdot \mathrm{mol}^{-1}\right)$ and the very long time for the system to reach the equilibrium state, $2160 \mathrm{~min}$, in comparison to $\mathrm{Fe}_{3} \mathrm{O}_{4}-\mathrm{GO}$. The data point to a chemical nature of the adsorption of tetracycline on $\mathrm{CH}_{4} \mathrm{~N}_{2} \mathrm{~S}-\mathrm{Fe}_{3} \mathrm{O}_{4}-\mathrm{GO}$ and the formation of near-covalent bonds between sorbent and sorbate. However, the lower regeneration capacity of this new adsorbent can be a drawback, since its adsorption capacity decreased from 148 to $52 \mathrm{mg} \cdot \mathrm{g}^{-1}$ after five cycles. Different from the reported data, Zhu et al. (2018) reported that the Freundlich model better fitted the adsorption of tetracycline onto Ca-alginate-GO, described as a heterogeneous surface adsorbent. Yet, both Langmuir and Freundlich models were tested and the coefficients of determination were almost equal, 0.9938 and 0.9986, respectively. Moreover, the authors showed no sufficient evidences of the heterogeneous arrangement of active sites on Ca-alginate-GO surface, and a more focused study should be performed to unravel this mechanism.

The adsorption of pharmacological hormones (17 $\beta$-estradiol and $17 \alpha$-ethynyl estradiol) onto carbonaceous adsorbents was performed by Jiang et al.

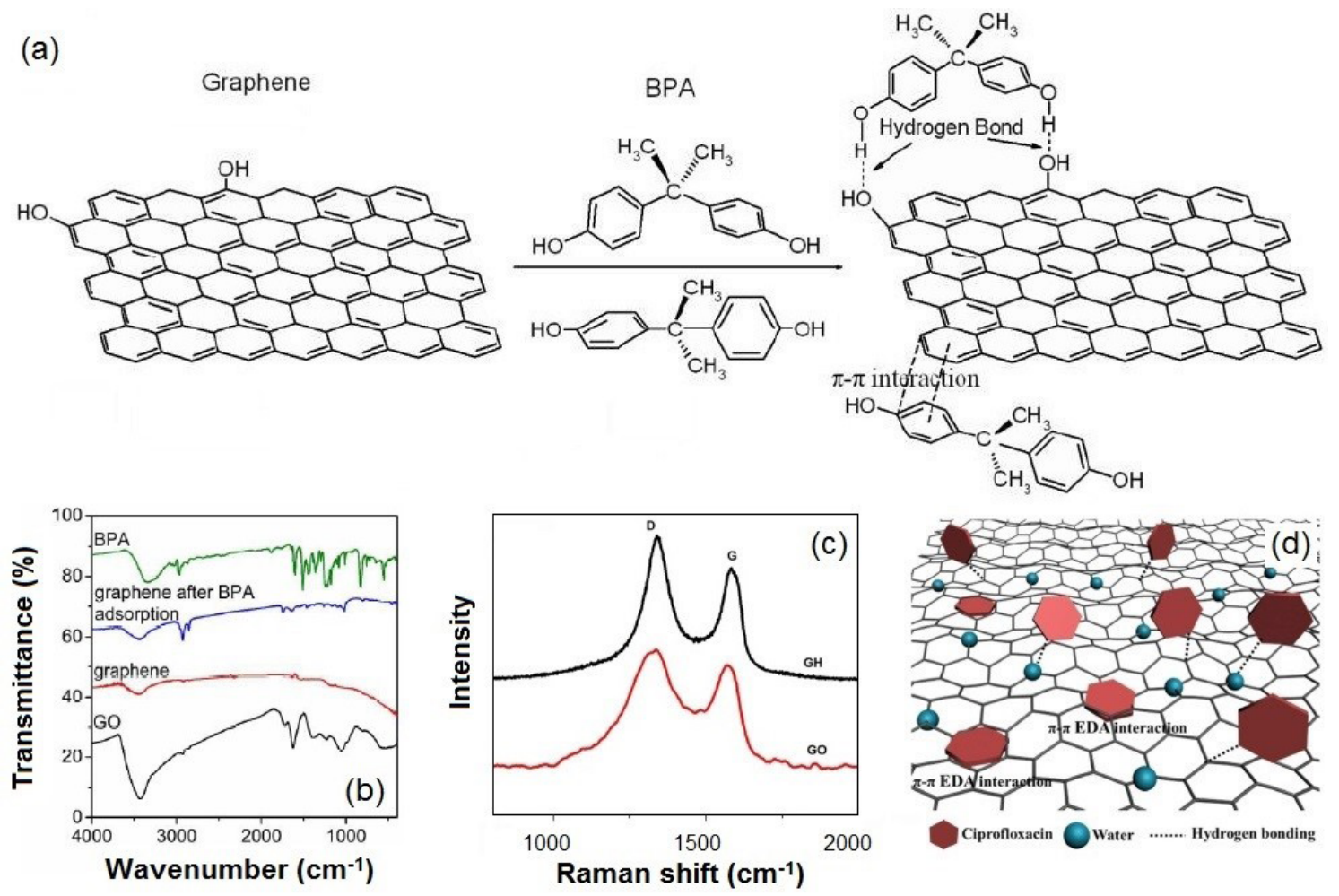

Figure 7. (a) Bisphenol A captured by graphene via H-bond and $\pi-\pi$ interactions (reproduced from Ma et al. (2015), with permission from Springer Nature, Copyright 2018); (b) FTIR spectra of bisphenol-A, exfoliated graphene oxide (GO), graphene and graphene-BPA (reproduced from Ma et al. (2015), with permission from Springer Nature, Copyright 2018); (c) Raman spectra of graphene oxide (GO) formed after oxidation of graphite and graphene hydrogel (GH) (reproduced from Xu et al. (2012), with permission from the American Chemical Society, Copyright 2018); (d) $\pi-\pi$ interactions of ciprofloxacin and water over graphene plane (reproduced from Xu et al. (2012), with permission from the American Chemical Society, Copyright 2018). 
(2017a), who tested different carbon-based adsorbents, including multi-walled carbon nanotubes (MWCNT) and graphene oxide nanosheets, and made a comparison between the adsorption capacity reached with each adsorbent. Equilibrium studies were performed and the Freundlich isotherm was applied to obtain the adsorption parameters. The results showed an adsorption capacity for GO of $64.39 \mathrm{mg} \cdot \mathrm{g}^{-1}$. The study of a pre-loading of Natural Organic Matter (NOM) before the adsorption process showed that the competition of NOM decreased the estrogen adsorption by all adsorbents evaluated. Previous kinetic studies showed that the system reached the equilibrium after $1440 \mathrm{~min}$ for all adsorbents (Jiang et al., 2016). Then, $\beta$-cyclodextrin/poly(L-glutamic acid) supported magnetic-GO was synthetized to adsorb $17 \beta$-estradiol and equilibrium experiments presented higher maximum adsorption capacity, $85.80 \mathrm{mg} \cdot \mathrm{g}^{-1}$ (298 $\mathrm{K}$, with Langmuir's and pseudo-second-order models fitted better), an increase of $33.25 \%$ in comparison to the result obtained for GO.

The summarized data revealed that adsorptions of pharmaceutical compounds are better fitted by the models of Langmuir for equilibrium and pseudo- second-order for kinetics. The data presented in Table 2 show that, unlike activated carbons and clay-based adsorbents, the specific surface area does not have a major influence in the adsorption efficiency nor in the adsorbent capacity, since the surface interactions play a major role in the adsorption mechanisms (Eigler and Hirsch, 2014; Kyzas et al., 2014).

\section{Oil and its derivatives}

Due to the substantial increase of crude oil exploration, as well as the scale-up of production of petroleum derivatives, their main and related activities have caused detrimental and long-term degradation of different ecosystems (Ge et al., 2016; Gu et al., 2014). The adsorption of oil emulsions onto graphenebased materials has been growing in concern and successfully explored in recent studies, showing outstanding adsorption capacities. Newly developed cutting-edge adsorbents consist of functionalized graphene-decorated sponges (Figure 8a-d), hydrogels (Figure 8e) and xerogels; many of them are decorated with magnetic metallic nanospheres and generally present high recyclability (Nguyen et al., 2012). (a)

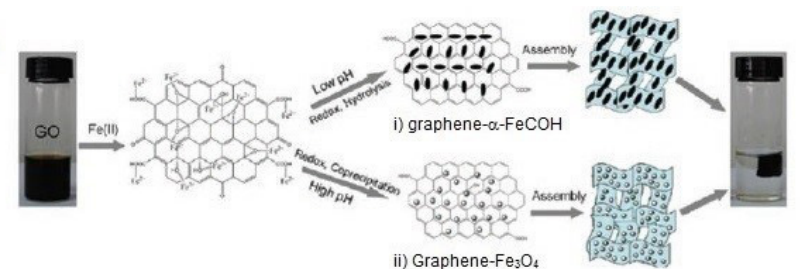

(c)

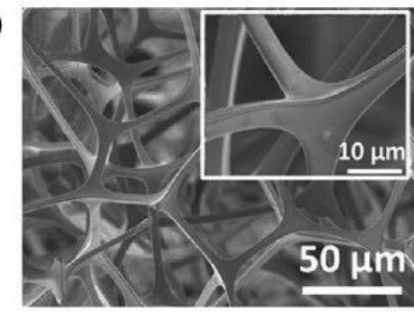

(f)

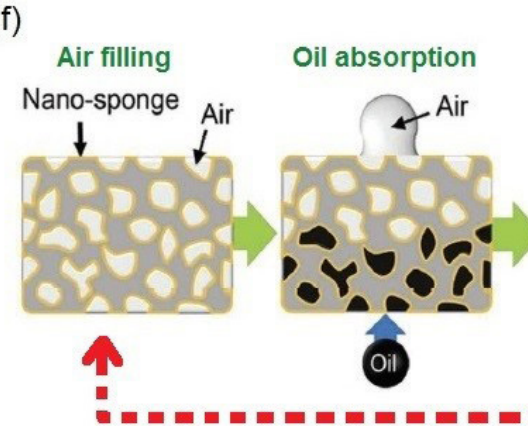

(d)

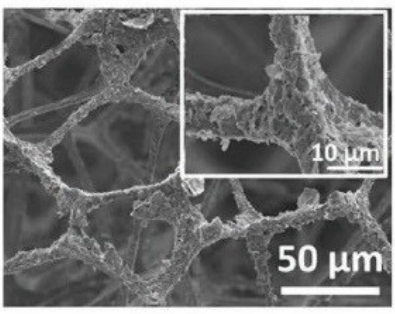

(b)

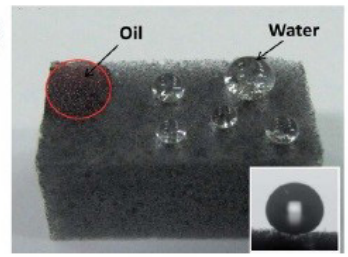

(e)

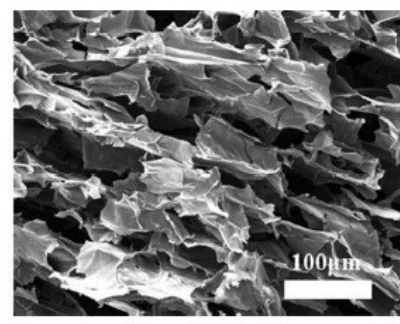

Oil/Bubble

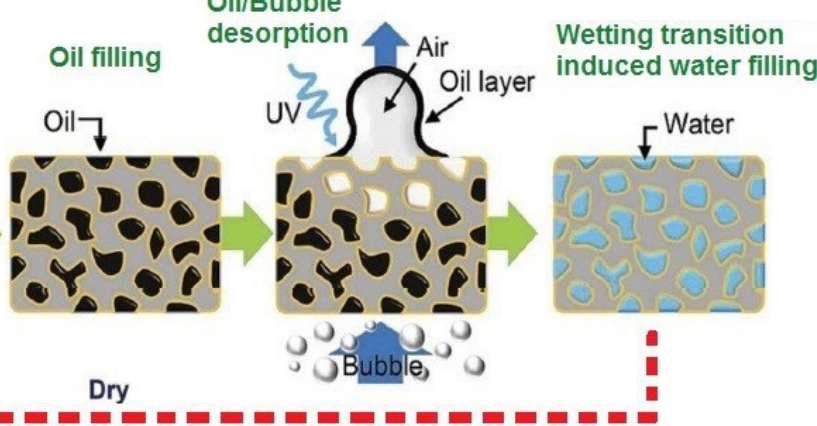

Figure 8. (a) Schematic illustration of the mechanism of formation of graphene/iron oxide hydrogels (reproduced from Ge et al. (2016), with permission from John Wiley and Sons, Copyright 2018); (b) wide scale synthetized oilphilic graphene sponge (reproduced from Nguyen et al. (2012), with permission from the Royal Society of Chemistry, Copyright 2018); (c) SEM images of the bare sponge (d) and the graphene-coated sponge; (e) SEM image of the icetemplate growing graphene hydrogel (reproduced from Nguyen et al. (2012), with permission from the Royal Society of Chemistry, Copyright 2018); (f) absorption and desorption mechanism with UV-responsive wettability and airbubble flow (adapted from Kim et al. (2015), with permission from Springer Nature, Copyright 2018). 
Crude oil removal from wastewater by adsorption onto N-doped-reduced-GO presented a maximum

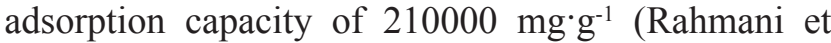
al., 2018). Samples containing diesel oil emulsion showed maximum adsorption capacity of $25000 \mathrm{mg} \cdot \mathrm{g}^{-}$ ${ }^{1}$ and $733 \mathrm{mg}^{\cdot} \mathrm{g}^{-1}$, for GO (Huang and Yan, 2018) and thermally-reduced GO (T-rGO) (Diraki et al., 2018), respectively; moreover, the Freundlich isotherm model fitted the experimental data better for both GO and T-rGO, confirming the highly heterogeneity of the adsorption sites. Kinetic experiments showed that the oil emulsion reached the equilibrium state after 45 min when adsorbed by GO, with the pseudosecond-order model presenting better adjustment to experimental kinetic data (Huang and Yan, 2018); the adsorption onto T-rGO was noticeably faster, when $90 \%$ of oil emulsion reached the equilibrium state after 10 minutes (Diraki et al., 2018). For GO sorption evaluation, kinetic experiments were performed at different temperatures and showed that the adsorption capacity increased with the increase of temperature, while thermodynamic parameters pointed to a spontaneous physiosorption process (Huang and Yan, 2018). The intermolecular interactions showed that $\pi$-London and van der Waals forces govern the adsorption mechanisms, since the hydrocarbon molecules do not present chemisorption groups (Diraki et al., 2018). The adsorbent high oil selectivity was the reason for the highly efficient separation of the emulsified diesel oil present in the oil-water emulsion from the graphene aerogel. Furthermore, the sorbent recyclability was evaluated as being one of the remarkable characteristics of graphene aerogel. The tests were performed under compressive strain-stress and showed high adsorption capacity after 10 cycles. External $\mathrm{O}_{2}$ bubble flow may be added to the system (Figure 8f) in order to accelerate the oil desorption process, since it may take too much time only with UV irradiation (Kim et al., 2015).

\section{Volatile Organic Compounds (VOC)}

According to the World Health Organization, a large variety of volatile organic compounds (VOCs) are responsible for development of cancer in people all over the world. To minimize the damage caused by VOCs in the environment and human health, GO based materials have been recently employed by several researchers for VOCs treatment (Chabot et al., 2014). VOCs adsorption is strongly influenced by the temperature and the presence of water vapor. Moreover, the presence of oxygen-content groups on the surface of GO (such as hydroxide, carboxyl, phenol, among others) gives it a high hydrophilicity. In this sense, the removal of these groups generates more $\mathrm{sp}^{2}$ carbon atoms on the adsorbent, that would weaken the reaction between water vapor and the adsorbent, leading to an increase of the adsorption of VOCs onto GO based adsorbents (Zhang et al., 2017; Asai et al., 2011).

In order to detect the presence of VOCs in the air, Nag et al. (2014) evaluated six types of r-GO based sensors. It was observed that cyclodextrinfunctionalized rGO (CD-rGO) had a major nonpolar interaction and low disconnection capability, which tended to be used as reference. Van der Waals interactions between the chemical groups present in the conductive cyclodextrin nanocomposites and the VOC can be correlated to the amplitude of their chemoresistive response; in this sense, CD-rGO showed high sensitivity to detect VOC presence in air and water (Kumar et al., 2012; Feller and Grohens, 2004).

The use of reduced graphene oxide ( $\mathrm{rGO}$ ) as adsorbent of benzene and toluene was studied by $\mathrm{Yu}$ et al. (2017). A good adsorption capacity was obtained for these two toxic and carcinogenic pollutants, 276.4 and $304.4 \mathrm{mg} \cdot \mathrm{g}^{-1}$ for benzene and toluene, respectively. Adsorption dynamics showed that the functional groups on the rGO surface played a significant role in benzene and toluene adsorption; $\pi-\pi$ and hydrophobic interactions govern the adsorption mechanisms; moreover, the methyl group of toluene can interact with the O-containing groups at the surface of $\mathrm{rGO}$ through hydrogen bonding, which can enhance the interaction between toluene and rGO.

\section{ATMOSPHERIC POLLUTANTS}

In face of the advance of industrial power, gaseous pollutants emissions have been substantially increased over the decades and have become one of the most important challenges of the modern society. $\mathrm{CO}_{2}$ is the atmospheric pollutant which generates major concern nowadays because of its widespread emission from the combustion from automobiles, forest fires and industrial processes. Its capacity to block the infrared irradiation in the stratospheric layer aggravates the greenhouse effect and, consequently, global warming (Haque et al., 2017). Another chemical species which causes severe damage to the atmosphere is chlorofluorocarbon (CFC), a gas used in freezers, refrigerators and air-conditioners. $\mathrm{CFC}$ has the property to react with $\mathrm{O}_{3}$ and cause damage to the ozone layer even in residual volumes, responsible for filtering the sunlight UV irradiation (Zhao et al., 2011). Moreover, gaseous inorganic pollutants, such as $\mathrm{SO}_{2}$ and $\mathrm{NO}_{2}$, can react with water vapor present in the air and clouds, causing the acid rain phenomenon (Babu et al., 2016). The environmental consequences of acid rain in big cities are observed in monument and building damages, flora destruction, lowering of soil $\mathrm{pH}$, water body contamination and human diseases; nevertheless, it is rather difficult to quantify them economically (Singh and Agrawal, 2008). 
Between the treatments indicated to avoid emissions of gaseous pollutants into the atmosphere, one can cite: gas-liquid absorption ( $\mathrm{Li}$ et al., 2013; Horikawa et al., 2004), photocatalytic reduction (Wang and Wang, 2016; Sakakura et al., 2007), gas washing (Xiao et al., 2014; Liao and Siddoway, 1996), bio-, micro- and nanofiltration (Sarfraz and BaShammakh, 2018; Soreanu et al., 2013; Montebello et al., 2012) and gas-solid adsorption (Yuan et al., 2018; Lalitha et al., 2017). However, gas-liquid absorption is one of the most effective processes to treat gaseous pollutants and decrease the emission of greenhouse effect gases in the atmosphere. Such treatments are widely employed in oil refineries worldwide to degas mercaptans, thiocompounds and $\mathrm{SO}_{X}, \mathrm{NO}_{X}$ compounds which have strong potential to cause acid rain. Develop an alternative to overcome the drawbacks of the use of the classical monoethlyleneamine and diethyleneamine (MEA/DEA) as capture agent for $\mathrm{CO}_{2}$ and other atmospheric pollutants has been pursued by many researchers. Among the candidates to substitute or to be used as enhancers of liquid-aminebased aqueous solutions, numerous alternative solid absorbents have been designed and investigated, such as zeolites, metal-organic frameworks, mesoporous silicas, hydrotalcites, activated carbons, etc. (Bae et al., 2013; Zhang et al., 2014; Drese et al., 2009; Quang et al., 2016; Gao et al., 2013; Dutta et al., 2014; Zhou et al., 2014). Furthermore, carbon nanomaterials including carbon nanotubes, graphene and graphene oxides have been extensively investigated for $\mathrm{CO}_{2}$ adsorption (Tamilarasan and Ramaprabhu, 2015; Su et al., 2014; Mishra and Ramaprabhu, 2014; Shen et al., 2015; Chowdhury and Balasubramanian, 2016). The application of functionalized graphene or graphene oxide as adsorbent of air pollutants has been studied and new mechanisms for enhancing the removal efficiency, as well as adsorbent improvements have been proposed (Chowdhury and Balasubramanian, 2016).

\section{Gaseous pollutants capture}

It is rather difficult to find scientific works about experimental in situ adsorption of gaseous pollutants in the literature, the majority of them being related to adsorption simulation and molecular dynamics theoretical studies (such as DFT) (Razmkhah et al., 2018; Kumar et al., 2017; Faye et al., 2016). Computational simulation with mathematical models is helpful to predict and understand the sorbent-sorbate interactions, adsorption mechanisms and the influence of graphene structural properties on the nanoscale (Kumar et al., 2017). Yet, among the papers reporting real gaseous compound removal, a great part is divided between liquid-solid absorption and gas-solid adsorption. Among the last ones, the adsorption of $\mathrm{CO}_{2}$ and $\mathrm{CH}_{4}$ are the overwhelming majority nowadays, as summarized in Table 3.

Tamilarasan and Ramaprabhu (2015) evaluated the gain in efficiency of $\mathrm{CO}_{2}$ adsorption onto polymerized ionic liquid (PIL) functionalized graphene. An ionic liquid (IL) or polymerized ionic liquid (PIL) was integrated with graphene to achieve enhanced carbon dioxide adsorption properties. Graphene was non-covalently functionalized by IL or PIL, and the carbon dioxide adsorption and desorption properties were determined at pressures below $100 \mathrm{kPa}$. Upon functionalization, IL uniformly covers the graphene surface, while PIL forms highly distributed porous nanoparticles. The PIL functionalized graphene shows $22 \%$ higher adsorption capacity than graphene, but lower than amino functionalized carbon nanotubes (CNT-APTS) in a TVSA dual column process, applied by $\mathrm{Su}$ et al. (2014); moreover, IL functionalization improves $\mathrm{CO}_{2}$ capture only by $2 \%$. Interestingly, the adsorption capacities of the integrated systems are higher than those of the individual constituents (either graphene or IL or PIL). It is found that PIL functionalization offers more favorable adsorption and higher adsorbate retention with high adsorption energy, with adsorption capacities of graphene, graphene-IL and graphene-PIL of 695, 710 and 794 $\mathrm{mmol} \cdot \mathrm{g}^{-1}$, respectively. Isosteric heats of adsorption are calculated to be in the range of $18-28 \mathrm{~kJ} \cdot \mathrm{mol}^{-1}$, suggesting an ease of adsorbent regeneration. These results encourage the integration of PIL with other high surface area nanostructures for further improvement in the adsorption capacity. Table 3 summarizes different functionalized graphene nanocomposites employed as adsorbents of gaseous pollutants.

Song et al. (2017) synthetized melaminefunctionalized graphene as additive in the $\mathrm{CO}_{2}$ gas-liquid absorption process. Monoethanolamine (MEA) was used in aqueous solution as the basic $\mathrm{CO}_{2}$ absorbent; the absorbance performance of $\mathrm{CO}_{2}$ in the (MEL- GO) -MEA - $\mathrm{H}_{2} \mathrm{O}$ solid-liquid hybrid absorbent for different mass concentrations of MEL-GO in 30 wt \% MEA aqueous solution was investigated. FTIR spectra exhibited several bands in the regions 3469 $3130 \mathrm{~cm}^{-1}$, corresponding to the melamine spectrum and due to intermolecular hydrogen bonding. There are several strong peaks in the $1652-1437 \mathrm{~cm}^{-1}$ region attributable to the $\mathrm{C}-\mathrm{N}$ stretching and $\mathrm{NH}_{2}$ bending vibrations (Mirescu et al., 2012); other characteristic peaks indicate the existence of hydroxyl, carboxyl, and epoxide groups in GO; the MEL-GO spectra, compared with GO, showed that the peaks at $1727 \mathrm{~cm}^{-1}$ and 1384 $\mathrm{cm}^{-1}$ practically disappeared (Chatterjee et al., 2013; Liu et al., 2015). Experimental results showed that the (MEL-GO) solid absorbent can enhance the solubility of $\mathrm{CO}_{2}$ at lower mass concentrations of MEL-GO in MEA aqueous solution. This is attributed to the effect 
Table 3. Comparative study between the experimental data in the literature for adsorption of gaseous pollutants onto functionalized graphene.

\begin{tabular}{|c|c|c|c|c|c|c|}
\hline Adsorbent & $\begin{array}{l}\text { BET surface area } \\
\left(\mathrm{cm}^{2} \cdot \mathrm{g}^{-1}\right)\end{array}$ & Adsorbate & $\underset{\left(\mathbf{m m o l} \cdot \mathbf{g}^{-1}\right)}{\mathbf{q} \mathbf{m}}$ & $\begin{array}{c}\text { Operation } \\
\text { pressure } \\
(\mathrm{kPa}) \\
\end{array}$ & $\begin{array}{c}\mathbf{T} \\
(\mathbf{K})\end{array}$ & Reference \\
\hline 3D mesoporous graphene & 477 & $\mathrm{CO}_{2}$ & 0.68 & 106.6 & 273 & $\begin{array}{l}\text { Wang et al. } \\
\text { (2011) }\end{array}$ \\
\hline Graphene nanosheets & - & $\mathrm{CO}_{2}$ & 75 & 1,100 & 298 & $\begin{array}{l}\text { Mishra and } \\
\text { Ramaprabhu } \\
\text { (2012) }\end{array}$ \\
\hline Carbon Hollow fibers-Graphene & - & $\mathrm{CO}_{2}$ & 76 & 140 & 298 & $\begin{array}{l}\text { Elsabawy and } \\
\text { Fallatah (2018) }\end{array}$ \\
\hline Amine-CdS- graphene & - & $\mathrm{CO}_{2}$ & 0.08 & 10 & 298 & Cho et al. (2017) \\
\hline Azido-Terpyridine-r-GO & 440 & $\mathrm{CO}_{2}$ & 2.66 & 100 & 273 & $\begin{array}{l}\text { Zhou et al. } \\
\text { (2014) }\end{array}$ \\
\hline $\begin{array}{l}\text { Polyethyleneimine- } \mathrm{SiO}_{2}- \\
\text { Graphene }\end{array}$ & 32 & $\mathrm{CO}_{2}$ & 4.32 & $<100$ & 348 & $\begin{array}{l}\text { Yang et al. } \\
\text { (2013b) }\end{array}$ \\
\hline Polyaniline-graphene & - & $\mathrm{CO}_{2}$ & 75 & 1,100 & 298 & Ramaprabhu \\
\hline $\mathrm{Fe}_{3} \mathrm{O}_{4}$-Graphene & 98.2 & $\mathrm{CO}_{2}$ & 60 & 1,100 & 298 & $\begin{array}{c}\text { Mishra and } \\
\text { Ramaprabhu } \\
\text { (2014) }\end{array}$ \\
\hline $\mathrm{H}_{2}-\mathrm{r}-\mathrm{GO}$ & 344 & $\mathrm{CO}_{2}$ & 1.23 & 100 & 283 & $\begin{array}{c}\text { Tamilarasan and } \\
\text { Ramaprabhu } \\
\text { (2015) }\end{array}$ \\
\hline MIL-101-GO & 2950 & $\mathrm{CO}_{2}$ & 22.40 & 2,500 & 298 & $\begin{array}{l}\text { Zhou et al. } \\
\text { (2015) }\end{array}$ \\
\hline $\begin{array}{l}\text { [ButylMethylimidazolium] }\left[\mathrm{BF}_{4}\right. \\
\text { ]-r-GO }\end{array}$ & - & $\mathrm{CO}_{2}$ & 1.10 & 100 & 283 & $\begin{array}{c}\text { Tamilarasan and } \\
\text { Ramaprabhu } \\
\text { (2015) }\end{array}$ \\
\hline $\begin{array}{l}\text { Poly(methylimidazolium)[BF}]- \\
\text { r-GO }\end{array}$ & - & $\mathrm{CO}_{2}$ & 1.05 & 100 & 283 & $\begin{array}{c}\text { Tamilarasan and } \\
\text { Ramaprabhu } \\
(2015)\end{array}$ \\
\hline 3D-graphene & 3000 & $\mathrm{CH}_{4}$ & 12.40 & 3,600 & 298 & $\begin{array}{l}\text { Mahmoudian et } \\
\text { al. (2016) }\end{array}$ \\
\hline O-nanocarbon & 699 & $\mathrm{CH}_{4}$ & 2.27 & 100 & 273 & $\begin{array}{l}\text { Wang et al. } \\
\text { (2015) }\end{array}$ \\
\hline MIL-101-GO & 2950 & $\mathrm{CH}_{4}$ & 7.50 & 2,500 & 298 & $\begin{array}{l}\text { Zhou et al. } \\
\text { (2015) }\end{array}$ \\
\hline Cu-BTC-GO & 1677 & $\mathrm{CH}_{4}$ & 1.30 & 100 & 273 & $\begin{array}{l}\text { Huang et al. } \\
\text { (2014) }\end{array}$ \\
\hline Graphene nanosheets & 300 & $\mathrm{CH}_{4}$ & 3.24 & 20,000 & 253 & $\begin{array}{l}\text { Zhu and Zheng } \\
\text { (2016) }\end{array}$ \\
\hline GO-MOF-Cu & - & $\mathrm{NH}_{3}$ & 2.64 & - & 298 & $\begin{array}{l}\text { Petit et al. } \\
\text { (2010) }\end{array}$ \\
\hline $\mathrm{GO}-\mathrm{Cu}$ & 8 & $\mathrm{H}_{2} \mathrm{~S}$ & 0.80 & - & 298 & $\begin{array}{l}\text { Mabayoje et al. } \\
\text { (2012) }\end{array}$ \\
\hline GO & 268 & $\mathrm{SO}_{2}$ & 2.43 & 101.3 & 298 & $\begin{array}{c}\text { Babu et al. } \\
(2016)\end{array}$ \\
\hline
\end{tabular}

of the special two-dimensional structure of the solid absorbent, together with many amine parts from both solid and liquid absorbent. $\mathrm{CO}_{2}$ capture efficiency increased $10 \%$ when MEL-GO was used to enhance the absorption process. Despite the good results regarding gas-liquid absorption, MEL-GO was not yet tested as adsorbent of liquid pollutants; however, this may be achieved in a further study.. CdS nanoparticles were imprinted by amino-functionalized reduced graphene oxide (Figure 9c) and have been successfully tested in the catalytic reduction of $\mathrm{CO}_{2}$ by Cho et al. (2017) (Figure $9 \mathrm{~b}$ ). $\mathrm{CO}_{2}$ was converted into methane via photocatalytic reaction. Suggested mechanism for the amine functionalization of graphene oxide is presented in Figure 9a. Moreover, SEM photographs showed well defined sphere formats for CdS nanoparticles, which was reproduced even after the amino-functionalized GO anchoring (Figure 9e). TEM images exhibited CdS nanoparticles covering by amino-reduced graphene oxide (Amino-G) nanolayers (Figure 9f). Additionally high methane formation rate $(1.62 \mu \mathrm{mol} /(\mathrm{g} \mathrm{h}))$ was observed for Amino-G/CdS under $\mathrm{CO}_{2}$ at low pressure ( 0.1 bar) and visible light, result 20 times higher than GO grafted on CdS surface. 


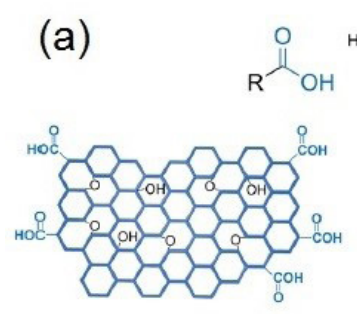

Graphene oxide

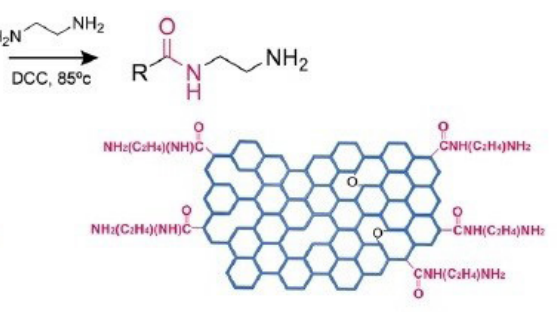

Amine-functionalized graphene

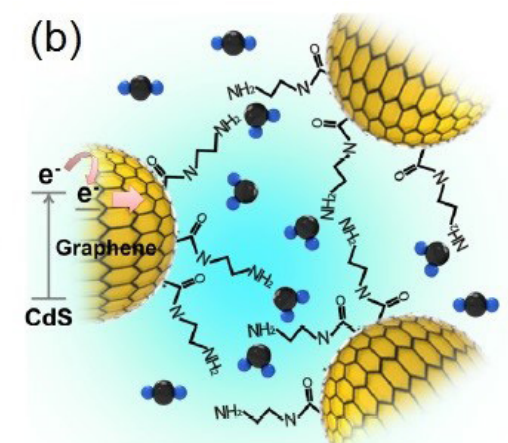

(c)

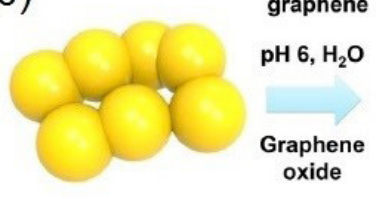

CdS nanoparticle

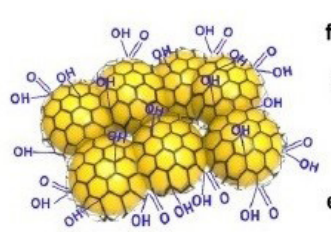

GO/CdS

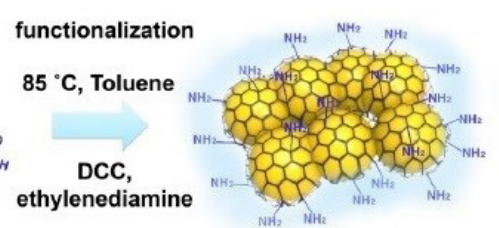

AG/CdS
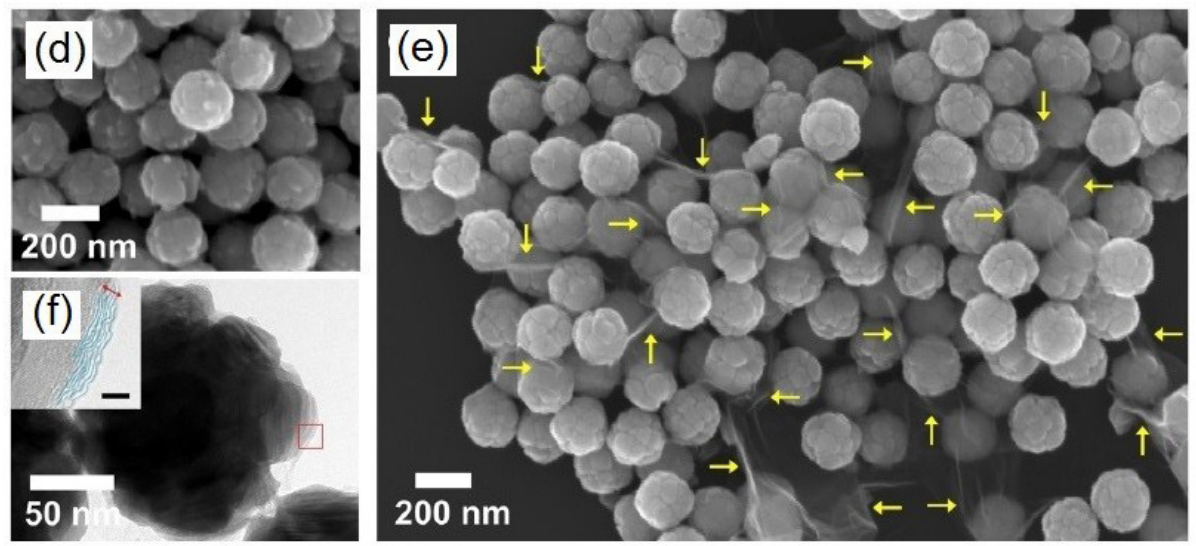

Figure 9. (a) Amine-functionalization synthesis of GO; (b) illustration of the proposed mechanism of $\mathrm{CO}_{2}$ photoreduction on the Amino-G/CdS; (c) schematic of the synthesis of the Amino-G/CdS; (d) SEM image of CdS nanoparticles; (e) SEM image of Amino-G/CdS; (f) TEM image of Amino-G/CdS (amino-G nanosheets covering spheres surface). Reproduced from Cho et al. (2017), with permission from the American Chemical Society, Copyright 2018.

The operational conditions of temperature and pressure in which the adsorption process takes place have fundamental importance, not only in terms of performance, but also in terms of operational costs. For adsorption of $\mathrm{CO}_{2}$ (Table 3), graphene nanosheets reached $76.00 \mathrm{mmol} \cdot \mathrm{g}^{-1}$ of adsorption capacity (Mishra and Ramaprabhu, 2012); however, the carbon fibergraphene composite obtained $75.00 \mathrm{mmol} \cdot \mathrm{g}^{-1}$ with a pressure eight times lower (Elsabawy and Fallatah, 2018). Table 3 also evidences that the adsorption capacity increases with the operational pressure; it is highlighted for $\mathrm{CO}_{2}$ data. This is an effect of the saturation of the adsorbent, which happens at medium and high pressures; this behavior is with regard to the gas-solid interactions, hence microporous structure contributes only at the level of an increase of the specific area of the adsorbent (Malbrunot et al., 1996). Zhu and Zheng (2016) evaluated the adsorption of methane onto graphene sheets and made a comparative study between the results obtained for graphene and the ones obtained for activated carbon and carbon black. Three kinds of carbon materials, graphene nanosheets, activated carbon and carbon black, showed specific surface areas of about $300 \mathrm{~m}^{2} \cdot \mathrm{g}^{-1}, 1118 \mathrm{~m}^{2} \cdot \mathrm{g}^{-1}$ and 76 $\mathrm{m}^{2} \cdot \mathrm{g}^{-1}$ and were selected for adsorption equilibrium testes within the temperature-pressure range from $253.15 \mathrm{~K}$ to $293.15 \mathrm{~K}$ and 0 to $8 \mathrm{MPa}$. Their maximum adsorption capacities at $293 \mathrm{~K}$ were $2.17,11.54$ and $1.15 \mathrm{nnmol} \cdot \mathrm{g}^{-1}$, for graphene nanosheets, activated carbon and carbon black, respectively. This behavior follows a tendency of increasing the adsorbed amount of gaseous pollutants with the increase of the sorbent specific surface area (Georgakilas et al., 2012), unlike adsorption in the liquid phase involving functionalized graphene, where the surface interactions are more determinant than the adsorbent porous structure (Yusuf 
et al., 2015). The Langmuir-Freundlich equation and a lattice theory based adsorption model were employed to determine the isosteric heat of adsorption and the molecular interaction energy between adsorbates, which presented the following values: 16.32-20.26 $\mathrm{kJ} \cdot \mathrm{mol}^{-1}, \quad 15.75-19.05 \mathrm{~kJ} \cdot \mathrm{mol}^{-1}$ and 11.91-12.35 $\mathrm{kJ} \cdot \mathrm{mol}^{-1}$ for activated carbon, the graphene nanosheets and carbon black, respectively.

Babu et al. (2016) first studied the adsorption of pure $\mathrm{SO}_{2}$ on graphene oxide $(\mathrm{GO})$ activated with $\mathrm{N}_{2}$ and compared with thermally treated $\mathrm{GO}$ at $150^{\circ} \mathrm{C}$ and $300^{\circ} \mathrm{C}$. The BET measured specific surface area for GO was $268 \mathrm{~m}^{2} \cdot \mathrm{g}^{-1}$ following the BET $\mathrm{N}_{2}$ adsorption method. Moreover, the $\mathrm{N}_{2}$ isotherm showed type IV hysteresis, where no accentuated increase in $\mathrm{N}_{2}$ adsorption occurs at low pressures, indicating the absence of extensive micropores (Ruthven, 1984), different from activated carbons. XPS spectra exhibited the characteristic GO C-O $(286.1 \mathrm{eV})$ and $\mathrm{O}-\mathrm{C}=\mathrm{O}(288.3 \mathrm{eV})$ bonding energies; the main peak at $284.4 \mathrm{eV}$ corresponds to the $\mathrm{sp}^{2}$ bonded carbons (C-C bonds). The system quickly reached the equilibrium state (after $10 \mathrm{~min}$ ), according to experimental kinetic data. The adsorption mechanism was found to be fundamentally different from conventional carbon materials such as activated carbon or carbon fibers. It was observed that $\mathrm{GO}$ binds $\mathrm{SO}_{2}$ only by physisorption $\left(\Delta \mathrm{H}_{\text {ads }} 18.04 \mathrm{~kJ} \cdot \mathrm{mol}^{-1}\right)$ and still the adsorption capacity was found to be comparable to traditional adsorbents like activated carbon or carbon molecular sieves. The 2D layered morphology, as well as the absence of extensive micropores well known to promote $\mathrm{SO}_{2}$ to $\mathrm{SO}_{3}$ conversion is responsible for the observed physisorption characteristics. GO dosage effect analysis showed that $\mathrm{SO}_{2}$ achieved its best adsorption capacity at $4.50 \mathrm{mmol} \cdot \mathrm{g}^{-1}$. This result was obtained at low operation pressure, in comparison to other reported data (Table 3), which required elevated pressure (up to $2000 \mathrm{kPa}$ ) to obtain similar adsorption capacities for $\mathrm{CH}_{4}$ (Zhu and Zheng, 2016; Zhou et al., 2015).

\section{CONCLUSIONS AND FUTURE RESEARCH NEEDS}

The application of functionalized graphene and its derivatives as adsorbents towards different organic pollutants is cutting-edge research which have raised the interest of several researchers across the globe. Graphene versatility is pointed out as a characteristic which can be explored in the most varied fields. In this sense, functionalization of graphene plays an important role in the adsorption of aqueous and gaseous pollutants, due to remarkable increases in the adsorption performance. For a better understanding of this phenomenon, this review investigated the interaction mechanisms between functionalized graphene and organic compounds in adsorptive processes of liquid and gaseous systems.

Sorption mechanisms are strongly related to the graphene surface properties. Moreover, these are reported as being primarily responsible for the sorbent capacity; $\pi-\pi$ interactions, electrostatic and van der Waals forces are depicted in several works as being the most representative for adsorption of several pollutants. Functional moieties can increase the availability of $\pi$-electrons in the system, contributing to the $\pi$-stacking interactions between the carbon basal plane and the aromatic structures of the adsorbate.

It was shown that the introduction of specific functional groups on carbonaceous nanomaterials surfaces and edges promoted relevant selectivity for the adsorption of some organic compounds. On the other hand, this new adsorbent may be inefficient towards other species of pollutants. Nevertheless the great sorption capacity, selectivity and high recyclability of functionalized graphene must be highlighted as strong points which motivate focused research.

Adsorption of gaseous pollutants, on the other hand, is described as more dependent on the adsorbent surface area, in comparison to liquid-solid adsorption. However, there are few in situ experimental works described in this field; hence, an in-depth study based on these observations is recommended.

Some challenges regarding the chemical functionalization must be faced by researchers worldwide, such as high production and operational costs, by-product release and their impact on the environment and human health, which are not entirely known. This is with no doubt a fertile field for further investigations. Nowadays few functionalized graphene-based nanomaterials have been tested and analyzed when compared to other well-known sorbents regarding toxicity. Thus, it is recommended that future studies evaluate the impact of the by-products on the environment and human health. Moreover, layered graphene nanosheets remain dispersed in aqueous media even after the adsorption, which makes it rather difficult to separate them from the adsorbate; separation process becomes a major concern from a large scale perspective. However, some works report that graphene dispersion effects can be minimized by introducing metallic oxides into the graphene and GO suspension, favoring their precipitation.

\section{NOMENCLATURE}

$\begin{array}{ll}\text { DFT } & \text { Density functional theory } \\ \text { BET } & \text { Brunauer, Emmett and Teller } \\ \text { XRD } & \text { X-ray diffraction } \\ \text { XPS } & \text { X-ray photoelectronic spectroscopy } \\ \text { TEM } & \text { transmission electrons microscopy } \\ \text { AFM } & \text { Atomic force microscopy }\end{array}$


FTIR Fourrier-transform infrared spectroscopy

VSM vibrating-sample magnetometer

GO graphene oxide

$\mathrm{r}-\mathrm{GO} \quad$ reduced graphene oxide

Chem-rGO chemically reduced graphene oxide

Amino-G amino-functionalized reduced

graphene oxide

Amino-G/CdS amino-functionalized reduced graphene oxide grafted on $\mathrm{CdS}$ nanoparticles

$\begin{array}{ll}\text { GNP } & \text { graphene nanoplatelets } \\ \text { CNT } & \text { carbon nanotubes } \\ \text { MWCNT } & \text { multi-walled carbon nanotubes } \\ \text { MMM } & \text { mixed-matrix membrane } \\ \text { NOM } & \text { natural organic matter } \\ \text { MSPE } & \text { magnetic solid-phase extraction } \\ \text { TVSA } & \text { temperature/vacuum swing adsorption } \\ \text { IL } & \text { ionic liquid } \\ \text { PIL } & \text { poly-ionic liquid } \\ \text { CD } & \text { cyclodextrin } \\ \text { VOC } & \text { volatile organic compound } \\ \text { MEA } & \text { monoethyleneamine } \\ \text { DEA } & \text { diethyleneamine } \\ \text { MEL } & \text { melamine } \\ \text { DMF } & \text { N, N-dimethylformamide } \\ \text { PSO } & \text { pseudo-second-order } \\ \text { PFO } & \text { pseudo-first-order } \\ \text { IPD } & \text { intra-particle diffusion } \\ \mathrm{q} & \text { adsorption capacity }\left(\mathrm{mg} \cdot \mathrm{g}^{-1}\right) \\ \mathrm{q}_{\mathrm{m}} & \text { maximum adsorption capacity }\left(\mathrm{mg} \cdot \mathrm{g}^{-1}\right) \\ \mathrm{C}_{\mathrm{e}} & \text { sorbate concentration at the } \\ \Delta \mathrm{H}_{\text {ads }} & \text { equilibrium }\left(\mathrm{mg} \cdot \mathrm{L}^{-1}\right) \\ \mathrm{S}_{\mathrm{BET}} & \text { variation of the adsorption enthalpy } \\ \mathrm{T} & \text { specific surface area }\left(\mathrm{m}^{2} \cdot \mathrm{g}^{-1}\right) \\ 2 \theta & \text { Temperature }\left(\mathrm{K} \text { or }{ }^{\circ} \mathrm{C}\right) \\ \mathrm{R}^{2} & \text { diffraction angle }(\mathrm{degree}) \\ & \text { coefficient of determination } \\ & \text { (dimensionless })\end{array}$

\section{ACKNOWLEDGMENTS}

The authors thank the financial support given by the Brazilian federal agencies Coordenação de Aperfeiçoamento de Pessoal de Nível Superior (CAPES) and Conselho Nacional de Desenvolvimento Científico e tecnológico (CNPq), process number 311133/2015-0, and the Pernambuco State agency Fundação de Apoio à Ciência e Tecnologia do Estado de Pernambuco (FACEPE), grant number IBPG-1917-3.06/16.

\section{REFERENCES}

Agarwal S., Tyagi I., Gupta V.K., Fakhri A. and Sadeghi N., Adsorption of toxic carbamate pesticide oxamyl from liquid phase by newly synthesized and characterized graphene quantum dots nanomaterials, J. Colloid Interface Sci. 478, 430-438, (2016). https://doi.org/10.1016/j. jcis.2016.06.029

Ahmed M.S. and Kim Y.-B., Amide-functionalized graphene with 1,4-diaminobutane as efficient metal-free and porous electrocatalyst for oxygen reduction, Carbon, 111, 577-586, (2017). https:// doi.org/10.1016/j.carbon.2016.10.029

Ahmed M.S., Park D. and Jeon S., Ultrasmall Pd $\mathrm{Mn}_{1}$. $\mathrm{m}_{\mathrm{x}}$ binary alloyed nanoparticles on graphene catalysts for ethanol oxidation in alkaline media, J. Power Sources, 308, 180-188, (2016). https://doi. org/10.1016/j.jpowsour.2015.10.025

Ai L., Zhang C. and Chen Z., Removal of methylene blue from aqueous solution by a solvothermalsynthesized graphene/magnetite composite, J. Hazard. Mater. 192, 1515-1524, (2011). https://doi. org/10.1016/j.jhazmat.2011.06.068

Akhavan O. and Ghaderi E., Escherichia coli bacteria reduce graphene oxide to bactericidal graphene in a self-limiting manner, Carbon, 50, 1853-1860, (2012). https://doi.org/10.1016/j. carbon.2011.12.035

Akpotu S.O. and Moodley B., Application of assynthesised MCM-41 and MCM-41 wrapped with reduced graphene oxide/graphene oxide in the remediation of acetaminophen and aspirin from aqueous system, J. Environ. Manage. 209, 205-215, (2018). https://doi.org/10.1016/j. jenvman.2017.12.037

Al-Khateeb L.A., Almotiry S. and Salam M.A., Adsorption of pharmaceutical pollutants onto graphene nanoplatelets. Chem. Eng. J. 248, 191-199, (2014). https://doi.org/10.1016/j.cej.2014.03.023

Andersson, D.I. and Hughes, D., Evolution of antibiotic resistance at non-lethal drug concentrations. Drug Resist. Update, 15, 162-172, (2012). https://doi. org/10.1016/j.drup.2012.03.005

Asai M., Ohba T., Iwanaga T., Kanoh H., Endo M., Campos-Delgado J., Terrones M., Nakai K. and Kaneko K., Marked adsorption irreversibility of graphitic nanoribbons for $\mathrm{CO}_{2}$ and $\mathrm{H}_{2} \mathrm{O}$, J. Am. Chem. Soc., 133, 14880-14883, (2011). https://doi. org/10.1021/ja205832z

Babu D.J., Kühl F.G., Yadav S., Markert D., Bruns M., Hampe M.J. and Schneider J.J., Adsorption of pure $\mathrm{SO}_{2}$ on nanoscaled graphene oxide, RSC Adv., 6, 36834-36839, (2016). https://doi.org/10.1039/ c6ra07518e

Bae T.H., Hudson M.R., Mason J.A., Queen W.L., Dutton J.J., Sumida K., Micklash K.J., Kaye S.S., Brown C.M. and Long J.R., Evaluation of cationexchanged zeolite adsorbents for post-combustion carbon dioxide capture, Energy Environ. Sci. 6, 128138, (2013). https://doi.org/10.1039/c2ee23337a 
Banerjee P., Das P., Zaman A. and Das P., Application of graphene oxide nanoplatelets for adsorption of ibuprofen from aqueous solutions: evaluation of process kinetics and thermodynamics, Process Safety Environ. Protect. 101, 45-53, (2016). https:// doi.org/10.1016/j.psep.2016.01.021

Becerril H.A., Mao J., Liu Z., Stoltenberg R.M., Bao Z. and Chen Y., Evaluation of solution-processed reduced graphene oxide films as transparent conductors, ACS Nano, 2, 463-470, (2008). https:// doi.org/10.1021/nn700375n

Begum H., Ahmed M.S., Cho S. and Jeon S., Simultaneous reduction and nitrogen functionalization of graphene oxide using lemon for metal-free oxygen reduction reaction, $\mathrm{J}$. Power Sources, 372, 116-124, (2017). https://doi. org/10.1016/j.jpowsour.2017.10.035

Bhunia P., Hwang E., Min M., Lee J., Seo S., Some S., and Lee H., A non-volatile memory device consisting of graphene oxide covalently functionalized with ionic liquid, Chem. Commun., 48, 913-915, (2012). https://doi.org/10.1039/ c1cc16225j

Bisht A., Srivastava M., R. Kumar R.M., Lahiri I. and Lahiri D., Strengthening mechanism in graphene nanoplatelets reinforced aluminum composite fabricated through spark plasma sintering, Mater. Sci. Eng. A, 695, 20-28, (2017). https://doi. org/10.1016/j.msea.2017.04.009

Bottari G., Herranz M.A., Wibmer L., Volland M., Rodríguez-Pérez L., Guldi D.M., Hirsch A., Martín N., D'Souza F. and Torres T., Chemical functionalization and characterization of graphenebased materials, Chem. Soc. Rev. 46, 4464-4500, (2017). https://doi.org/10.1039/c7cs00229g

Boruah P.K., Sharma B., Hussain N. and Das M.R., Magnetically recoverable $\mathrm{Fe}_{3} \mathrm{O}_{4}$ /graphene nanocomposite towards efficient removal of triazine pesticides from aqueous solution: Investigation of the adsorption phenomenon and specific ion effect, Chemosphere, 168, 1058-1067, (2017). https://doi. org/10.1016/j.chemosphere.2016.10.103

Brodie B.C., Sur le poids atomique du graphite. Ann. Chim. Phys. 59, 466-472, (1860).

Bueno R.A., Martínez J.I., Luccas R.F., del Árbol N.R., Munuera C., Palacio I., Palomares F.J., Lauwaet K., Thakur S., Baranowski J.M., Strupinski W., López M.F., Mompean F., García-Hernández M. and Martín-Gago J.A., Highly selective covalent organic functionalization of epitaxial graphene, Nat. Commun. 8, 15306, (2017). https://doi. org/10.1038/ncomms 15306

Cai M.-Q., Su J., Hu J.-Q., Wang Q., Dong C.-Y., Pan S.-D. and Jin M.-C., Planar graphene oxide-based magnetic ionic liquid nanomaterial for extraction of chlorophenols from environmental water samples coupled with liquid chromatographytandem mass spectrometry, J. Chromatogr. A, 1459, 38-46, (2016). https://doi.org/10.1016/j. chroma.2016.06.086

Cai N. and Larese-Casanova P., Application of positively-charged ethylenediamine-functionalized graphene for the sorption of anionic organic contaminants from water, J. Environ. Chem. Eng. 4, 2941-2951, (2016). https://doi.org/10.1016/j. jece.2016.06.004

Carvalho M.N., Abreu C.A.M., Benachour M., Sales D.C.S., Baraúna O.S. and da Motta Sobrinho M.A., Applying combined Langmuir-Freundlich model to the multi-component adsorption of BTEX and phenol on smectite clay. Adsorpt. Sci. Technol., 30, 691-699, (2012). https://doi.org/10.1260/02636174.30.8-9.691

Carvallho M.N., da Silva K.S., Sales D.C.S., Freire E.M., Sobrinho M.A.M., Ghislandi M.G., Dye removal from textile industrial effluents by adsorption on exfoliated graphite nanoplatelets: kinetic and equilibrium studies, Water Sci. Technol. 73, 2189-2198, (2016). https://doi.org/10.2166/ wst.2016.073

Chabot V., Higgins D., Yu A., Xiao X., Chen Z. and Zhang J., A review of graphene and graphene oxide sponge: Material synthesis and applications to energy and the environment, Energy Environ. Sci. 7, 1564-1596, (2014). https://doi.org/10.1039/ c3ee43385d

Chatterjee S., Layek R.K. and Nandi A.K., Changing the Morphology of polyaniline from a nanotube to a flat rectangular nanopipe by polymerizing in the presence of amino-functionalized reduced graphene oxide and its resulting increase in photocurrent, Carbon, 52, 509-519, (2013). https:// doi.org/10.1016/j.carbon.2012.10.003

Chavez-Sumarriva I., Van Steenberge P.H.M., and D'hooge D.R., New insights in the treatment of waste water with graphene: dual-site adsorption by sodium dodecylbenzene sulfonate, Ind. Eng. Chem. Res. 55, 9387-9396, (2016). https://doi. org/10.1021/acs.iecr.6b02302

Chen X. and Chen B., Macroscopic and spectroscopic investigations of the adsorption of nitroaromatic compounds on graphene oxide, reduced graphene oxide, and graphene nanosheets, Environ. Sci. Technol. 49, 6181-6189, (2015). https://doi. org/10.1021/es5054946

Chinthakindi S., Purohit A., Singh V., Tak V., Goud D.R., Dubey D.K. and Pardasani D., Iron oxide functionalized graphene nano-composite for dispersive solid phase extraction of chemical warfare agents from aqueous samples, J. Chromatogr. A, 1394, 9-17, (2015). https://doi. org/10.1016/j.chroma.2015.03.033 
Chiu N.F., Fan S.Y., Yang C.D. and Huang T.Y., Carboxyl-functionalized graphene oxide composites as SPR biosensors with enhanced sensitivity for immunoaffinity detection, Biosens. Bioelectron., 89, 370-376, (2017). https://doi. org/10.1016/j.bios.2016.06.073

Cho K.M., Kim K.H., Park K., Kim C., Kim S., Al-Saggaf A., Gereige I. and Jung H.-T., Amine-functionalized graphene/CdS composite for photocatalytic reduction of $\mathrm{CO}_{2}$, ACS Catal., 7, 7064-7069, (2017). https://doi.org/10.1021/acscatal.7b01908

Chouhan R.S., Pandey A., Qureshi A., Ozguz V. and Niazi J.H., Nanomaterial resistant microorganism mediated reduction of graphene oxide, Colloids Surf. B: Biointerfaces, 146, 39-46, (2016). https:// doi.org/10.1016/j.colsurfb.2016.05.053

Chowdhury S. and Balasubramanian R., Threedimensional graphene-based porous adsorbents for post-combustion $\mathrm{CO}_{2}$ capture. Ind. Eng. Chem. Res., 55, 7906-7916, (2016). https://doi. org/10.1021/acs.iecr.5b04052

Cobos M., González B., Fernández M.J. and Fernández M.D., Study on the effect of graphene and glycerol plasticizer on the properties of chitosan-graphene nanocomposites via in situ green chemical reduction of graphene oxide, Int. J. Biol. Macromol., 114, 599-613, (2018). https://doi. org/10.1016/j.ijbiomac.2018.03.129

Das R., Vecitis C.D., Schulze A. and Cao B., Recent advances in nanomaterials for water protection and monitoring, Chem. Soc. Rev., 46, 6946-7020, (2017). https://doi.org/10.1039/c6cs00921b

Das T.R., Patra S., Madhuri R. and Sharma P.K., Bismuth oxide decorated graphene oxide nanocomposites synthesized via sonochemical assisted hydrothermal method for adsorption of cationic organic dyes, J. Colloid Interface Sci., 509, 82-93, (2018). https://doi.org/10.1016/j. jcis.2017.08.102

Daukiya L., Mattioli C., Aubel D., Hajjar-Garreau S., Vonau F., Denys E., Reiter G., Fransson J., Perrin E., Bocquet M.-L., Bena C., Gourdon A. and Simon L., Covalent functionalization by cycloaddition reactions of pristine defect-free graphene, ACS Nano, 11, 627-634, (2017). https://doi.org/10.1021/ acsnano.6b06913

De Silva K.K.H., Huang H.-H., Joshi R.K. and Yoshimura M., Chemical reduction of graphene oxide using green reductants, Carbon, 119, 190-199, (2017). https://doi.org/10.1016/j.carbon.2017.04.025

Diraki A., Mackey H., McKay G. and Abdala A., Removal of oil from oil-water emulsions using thermally reduced graphene and graphene nanoplatelets, Chem. Eng. Res. Des., 137, 47-59, (2018). https://doi.org/10.1016/j. cherd.2018.03.030
Dong S., Sun Y., Wu J., Wu B., Creamer A.E. and Gao B., Graphene oxide as filter media to remove levofloxacin and lead from aqueous solution, Chemosphere, 150, 759-764, (2015). https://doi. org/10.1016/j.chemosphere.2015.11.075

Drese J.H., Choi S., Lively R.P., Koros W.J., Fauth D.J., Gray M.L. and Jones C.W., Synthesisstructure-property relationships for hyperbranched aminosilica $\mathrm{CO}_{2}$ adsorbents, Adv. Funct. Mater., 19, 3821-3832, (2009). https://doi.org/10.1002/ adfm.200901461

Dreyer D.R., Park S., Bielawski C.W. and Ruoff R.S., The chemistry of graphene oxide, Chem. Soc. Rev., 39, 228-240, (2010). https://doi.org/10.1039/ b917103g

Dutta S., Bhaumik A. and Wu K.C.W., Hierarchically porous carbon derived from polymers and biomass: effect of interconnected pores on energy applications, Energy Environ. Sci., 7, 3574-3592, (2014). https://doi.org/10.1039/c4ee01075b

Eigler S. and Hirsch A., Chemistry with graphene and graphene oxide - challenges for synthetic chemists, Angew. Chem. Int. Ed., 53, 2-21, (2014). https:// doi.org/10.1002/anie.201402780

Elsabawy K.M. and Ahmed M. Fallatah A.M., Fabrication of ultra-performance non-compact Graphene/Carbon Hollow Fibers/Graphene stationary junction like membrane for $\mathrm{CO}_{2}$-capture, Mater. Chem. Phys., 211, 264-269, (2018). https:// doi.org/10.1016/j.matchemphys.2018.02.042

Fan J., Chen D., Li N., Xu Q., Li H., He J. and Lu J., Bio-engineered graphene-based cage for efficient local enrichment and biodegradation of aqueous organic wastes, Sci. Rep., 7, 1271, (2017). https:// doi.org/10.1038/s41598-017-01539-0

Faye O., Raja A., Mittal V. and Beye A.C., $\mathrm{H}_{2} \mathrm{~S}$ adsorption on graphene in the presence of sulfur: A density functional theory study, Comp. Mater. Sci., 117, 110-119, (2016). https://doi.org/10.1016/j. commatsci.2016.01.034

Fei Y., Li Y., Han S. and Ma J., Adsorptive removal of ciprofloxacin by sodium alginate/graphene oxide composite beads from aqueous solution, J. Colloid Interface Sci., 484, 196-204, (2016). https://doi. org/10.1016/j.jcis.2016.08.068

Feller J.F. and Grohens Y., Evolution of electrical properties of some conductive polymer composite textiles with organic solvent vapours diffusion, Sensors Actuators B Chem., 97, 231-242, (2004). https://doi.org/10.1016/j.snb.2003.08.021

Feng Y., Liu H., Luo W., Liu E., Zhao N., Yoshino K. and Feng W. Covalent functionalization of graphene by azobenzene with molecular hydrogen bonds for long-term solar thermal storage. Sci. Rep., 3, 1-8, (2013). https://doi.org/10.1038/srep03260 
Ganesan V., Louis C. and Damodaran S.P., Graphene oxide-wrapped magnetite nanoclusters: a recyclable functional hybrid for fast and highly efficient removal of organic dyes from wastewater, J. Environ. Chem. Eng., 6, 2176-2190, (2018). https://doi.org/10.1016/j.jece.2018.03.026

Gao Y.S., Zhang Z., Wu J.W., Yi X.F., Zheng A.M., Umar A., O'Hare D. and Wang Q., Comprehensive investigation of $\mathrm{CO}_{2}$ adsorption on $\mathrm{Mg}-\mathrm{Al}-\mathrm{CO} 3$ LDH-derived mixed metal oxides, J. Mater. Chem. A, 1, 12782-12790, (2013). https://doi.org/10.1039/ c3ta13039h

Ge J., Zhao H., Zhu H., Huang J., Shi L.A. and Yu S.H., Advanced sorbents for oil-spill cleanup: recent advances and future perspectives, Adv. Mater., 28, 10459-10491, (2016). https://doi.org/10.1002/ adma.201601812

Gevaerd A., Blaskievicz S.F., Zarbin A.J.G., Orth E.S., Bergamini M.F. and Marcolino-Junior L.H., Nonenzymatic electrochemical sensor based on Imidazole-functionalized graphene oxide for progesterone detection, Biosens. Bioelectron., 112, 108-113, (2018). https://doi.org/10.1016/j. bios.2018.04.044

Georgakilas V., Otyepka M., Bourlinos A.B., Chandra V., Kim N., Kemp K.C., Hobza P., Zboril R. and Kim K.S., Functionalization of graphene: covalent and non-covalent approaches, derivatives and applications, Chem. Rev. 112, 6156-6214, (2012). https://doi.org/10.1021/cr3000412

Ghadim E.E., Manouchehri F., Soleimani G., Hosseini H., Kimiagar S. and Nafisi S., Adsorption properties of tetracycline onto graphene oxide: equilibrium, kinetic and thermodynamic studies, PLoS One. 8, 1-9, (2013). https://doi.org/10.1371/journal. pone.0079254

Ghadim E.E., Manouchehri F., Soleimani G., Hosseini H., Kimiagar S. and Nafisi S., Adsorption properties of tetracycline onto graphene oxide: equilibrium, kinetic and thermodynamic studies, PLoS One. 8, 1-9, (2013). https://doi.org/10.1371/journal. pone. 0079254

Ghislandi M., Tkalya E., Alekseev A., Koning C. and de With G., Electrical conductive behavior of polymer composites prepared with aqueous graphene dispersions, Appl. Mater. Today, 1, 88-94, (2015). https://doi.org/10.1016/j.apmt.2015.11.001

Gu J., Xiao P., Chen J., Liu F., Huang Y., Li G., Zhang J. and Chen T., Robust preparation of superhydrophobic polymer/carbon nanotube hybrid membranes for highly effective removal of oils and separation of water-in-oil emulsions, J. Mater. Chem. A, 2, 15268-15272, (2014). https:// doi.org/10.1039/c4ta01603c

Gupta A., Vidyarthi S.R. and Sankararamakrishnan N., Thiol functionalized sugarcane bagasse-a low cost adsorbent for mercury remediation from compact fluorescent bulbs and contaminated water streams, J. Environ. Chem. Eng. 2, 1378-1385, (2014). https://doi.org/10.1016/j.jece.2014.05.010

Gupta S.S., Chakraborty I., Maliyekkal S.M., Maark T.A., Pandey D.K., Das S.K. and Pradeep T., Simultaneous dehalogenation and removal of persistent halocarbon pesticides from water using graphene nanocomposites: A case study of lindane, ACS Sustainable Chem. Eng., 3, 1155-1163, (2015). https://doi.org/10.1021/acssuschemeng.5b00080

Gurunathan S., Han J.W., Eppakayala V. and Kim J.H., Microbial reduction of graphene oxide by Escherichia coli: A green chemistry approach, Colloids Surf. BBiointerfaces, 102, 772-777,(2013). https://doi.org/10.1016/j.colsurfb.2012.09.011

Hakami O., Zhang Y. and Banks C.J., Thiolfunctionalised mesoporous silica-coated magnetite nanoparticles for high efficiency removal and recovery of $\mathrm{Hg}$ from water, Water Res. 46, 3913-3922, (2012). https://doi.org/10.1016/j. watres.2012.04.032

Haque E., Pourazadi E., Sarkar S., Harris A.T., Minett A.I., Yanmaz E., Kim J.H., Kaneti Y.V., Ide Y., Yamauchi Y., and Hossain M.S.A., Boron functionalized graphene-organic frameworks for highly efficient $\mathrm{CO}_{2}$ capture, Chem. Asian J. 12, 283-288, (2017). https://doi.org/10.1002/ asia.201601442

Hauser A.W., Mardirossian N., Panetier J.A., HeadGordon M., Bell A.T., and Schwerdtfeger P., Functionalized graphene as a gatekeeper for chiral molecules: an alternative concept for chiral separation, Angew. Chem. Int. Ed. 53, 1-5, (2014). https://doi.org/10.1002/anie.201406608

He F., Wang W., Moon J.W., Howe J., Pierce E.M. and Liang L., Rapid removal of $\mathrm{Hg}$ (II) from aqueous solutions using thiol-functionalized Zn-doped biomagnetite particles, ACS Appl. Mater. Interfaces 4, 4373-4379, (2012). https://doi.org/10.1021/ am301031g

Heidari H. and Razmi H., Multi-response optimization of magnetic solid phase extraction based on carbon coated $\mathrm{Fe}_{3} \mathrm{O}_{4}$ nanoparticles using desirability function approach for the determination of the organophosphorus pesticides in aquatic samples by HPLC-UV, Talanta, 99, 13-21, (2012). https://doi. org/10.1016/j.talanta.2012.04.023

Hiew B.Y.Z., Lee L.Y., Lee X.J., ThangalazhyGopakumar S., Gan S., Lim S.S., Pan G.T., Yang T.C.K., Chiu W.S. and Khiew P.S., Review on synthesis of $3 \mathrm{D}$ graphene-based configurations and their adsorption performance for hazardous water pollutants, Process Saf. Environ. Prot. 116, 262-286, (2018). https://doi.org/10.1016/j. psep.2018.02.010 
Ho Y.S. and McKay G., Pseudo-second order model for sorption processes, Proc. Biochem. 34, 451465, (1999). https://doi.org/10.1016/s00329592(98)00112-5

Ho Y.S., Porter J.F. and McKay G., Equilibrium isotherm studies for the sorption of divalent metal ions onto peat: copper, nickel and lead single component systems, Water Air Soil Pollut. 141, 1-33, (2002).

Horikawa M.S., Rossi F., Gimenes M.L., Costa C.M.M., and da Silva M.G.C., Chemical absorption of $\mathrm{H}_{2} \mathrm{~S}$ for biogas purification, Braz. J. Chem. Eng. 21, 415-422, (2004). https://doi.org/10.1590/ s0104-66322004000300006

$\mathrm{Hu}$ X. and Zhou Q. Health and ecosystem risks of graphene. Chem. Rev. 113, 3815-3835, (2013). https://doi.org/10.1021/cr300045n

Huang J. and Yan Z., Adsorption mechanism of oil by resilient graphene aerogels from oil-water emulsion, Langmuir. 34, 1890-1898, (2018). https://doi.org/10.1021/acs.langmuir.7b03866

Huang W., Zhou X., Xia Q., Peng J., Wang H. and Li Z., Preparation and Adsorption Performance of $\mathrm{GrO} @ \mathrm{Cu}-\mathrm{BTC}$ for Separation of $\mathrm{CO}_{2} / \mathrm{CH}_{4}$, Ind. Eng. Chem. Res., 53, 11176-11184, (2014). https:// doi.org/10.1021/ie501040s

Huang Y., Tang J., Gai L., Gong Y., Guan H., He R. and Lyu H., Different approaches for preparing a novel thiol-functionalized graphene oxide/Fe-Mn and its application for aqueous methylmercury removal, Chem. Eng. J. 319, 229-239, (2017). https://doi. org/10.1016/j.cej.2017.03.015

Hummers W.S. and Offeman R.E., Preparation of graphitic oxide. J. Am. Chem. Soc. 80, 1339-1339, (1958). https://doi.org/10.1021/ja01539a017

Im K., Nguyen D.N., Kim S., Kong H.J., Kim Y., Park C.S., Kwon O.S. and Yoon H. Graphene-Embedded Hydrogel Nanofibers for Detection and Removal of Aqueous-Phase Dyes. ACS Appl. Mater. Interfaces, 9, 10768-10776, (2017). https://doi.org/10.1021/ acsami.7b01163

Jiang L., Liu Y., Liu S., Zeng G., Hu X., Hu X., Guo Z., Tan X., Wang L., and Wu Z., Adsorption of estrogen contaminants by graphene nanomaterials under natural organic matter preloading: comparison to carbon nanotube, biochar, and activated carbon, Environ. Sci. Technol. 51, 6352-6359, (2017a). https://doi.org/10.1021/acs.est.7b00073

Jiang L., Liu Y., Liu S., Hu X., Zeng G., Hu X., Liu S., Liu S., Huang B., Li M., Fabrication of $\beta$-cyclodextrin/ poly (L-glutamic acid) supported magnetic graphene oxide and its adsorption behavior for $17 \beta$-estradiol, Chem. Eng. J. 308, 597-605, (2017b). https://doi. org/10.1016/j.cej.2016.09.067

Jiang L.H., Liu Y.G., Zeng G.M., Xiao F.Y., Hu X.J., Hu X., Wang H., Li T.T., Zhou L. and Tan X.F., Removal of $17 \beta$-estradiol by few-layered graphene oxide nanosheets from aqueous solutions: External influence and adsorption mechanism, Chem. Eng. J. 284, 93-102, (2016). https://doi.org/10.1016/j. cej.2015.08.139

Kenry, Lee W.C., Loh K.P. and Lim C.T., When stem cells meet graphene: opportunities and challenges in regenerative medicine. Biomaterials, 155, 236-250, (2018). https://doi.org/10.1016/j. biomaterials.2017.10.004

Kerkez-Kuyumcu Ö., Bayazit Ş.S. and Salam M.A., Antibiotic amoxicillin removal from aqueous solution using magnetically modified graphene nanoplatelets, J. Ind. Eng. Chem. 36, 198-205, (2016). https://doi.org/10.1016/j.jiec.2016.01.040

Khan A., Wang J., Li J., Wang X., Chen Z., Alsaedi A., Hayat T., Chen Y. and Wang X., The role of graphene oxide and graphene oxide-based nanomaterials in the removal of pharmaceuticals from aqueous media: a review, Environ. Sci. Pollut. Res. 24, 7938-7958, (2017). https://doi. org/10.1007/s11356-017-8388-8

Khurana I., Shaw A.K., Bharti, Khurana J.M. and Rai P.K., Batch and dynamic adsorption of Eriochrome Black $\mathrm{T}$ from water onmagnetic graphene oxide: Experimental and theoretical studies, Chem. Eng. J. 6, 468-477, (2018). https://doi.org/10.1016/j. jece.2017.12.029

Kim D.H., Jung M.C., Cho S.-H., Kim S.H., Kim H.-Y., Lee H.J., Oh K.H. and Moon M.-W., UVresponsive nano-sponge for oil absorption and desorption, Sci. Rep. 5, 12908, (2015). https://doi. org/10.1038/srep 12908

Kovarícek P., Vrkoslav V., Plsek J., Bastl Z., Fridrichová M., Drogowska K. and Kalbác M., Extended characterization methods for covalent functionalization of graphene on copper, Carbon, 118, 200-207, (2017). https://doi.org/10.1016/j. carbon.2017.03.020

Kovtyukhova N.I., Ollivier P.J., Martin B.R., Mallouk T.E., Chizhik S.A., Buzaneva E.V. and Gorchinskiy A.D., Layer-by-layer assembly of ultrathin composite films from micron-sized graphite oxide sheets and polycations, Chem. Mater. 11, 771-778, (1999). https://doi.org/10.1021/cm981085u

Kyzas G.Z., Bikiaris D.N., Seredych M., Bandosz T.J. and Deliyanni E.A., Removal of dorzolamide from biomedical wastewaters with adsorption onto graphite oxide/poly(acrylic acid) grafted chitosan nanocomposite, Bioresour. Technol. 152, 399-406, (2014). https://doi.org/10.1016/j. biortech.2013.11.046

Kyzas G.Z., Fu J., Lazaridis N.K., Bikiaris D.N. and Matis K.A., New approaches on the removal of pharmaceuticals from wastewaters with adsorbent materials, J. Molecular Liq. 209, 87-93, (2015a). https://doi.org/10.1016/j.molliq.2015.05.025 
Kumar B., Castro M. and Feller J.F., Materials selfassembly and fabrication in confined spaces, $\mathrm{J}$. Mater. Chem. 22, 10382-10405, (2012).

Kumar S., Meenakshi and Sharma H., Effect of gas adsorption on graphene nanoribbons: a Density Functional Theory, Mater. Today: Proceedings, 4, 10441-10445, (2017). https://doi.org/10.1016/j. matpr.2017.06.396

Kyhl L., Bisson R., Balog R., Groves M.N., Kolsbjerg E.L., Cassidy A.M., Jørgensen J.H., Halkjær S., Miwa J.A., Čabo A.G., Angot T., Hofmann P., Arman M.A., Urpelainen S., Lacovig P., Bignardi L., Bluhm H., Knudsen J., Hammer B. and Hornekaer L., Exciting $\mathrm{H}_{2}$ molecules for graphene functionalization, ACS Nano, 12, 513-520, (2018). https://doi.org/10.1021/acsnano.7b07079

Lalitha M., Lakshmipathia S. and Bhatia S.K., Edge functionalised \& Li-intercalated 555-777 defective bilayer graphene for the adsorption of $\mathrm{CO}_{2}$ and $\mathrm{H}_{2} \mathrm{O}$, Appl. Surf. Sci. 400, 375-390, (2017). https:// doi.org/10.1016/j.apsusc.2016.12.144

Larijani H.T., Ganji M.D. and Jahanshahi M., Trends on the amino acids adsorption onto the graphene and graphene oxide surface: A dispersion corrected DFT study, RSC Adv. 5, 92843-92857, (2015). https://doi.org/10.1039/c5ra16683g

Lavin-Lopez M.P., Paton-Carrero A., Sanchez-Silva L., Valverde J.L. and Romero A., Influence of the reduction strategy in the synthesis of reduced graphene oxide, Adv. Powder Technol. 28, 3195-3203, (2017). https://doi.org/10.1016/j.apt.2017.09.032

Lazarevic-Pasti T., Anicijevic V., Baljozovic M., Vasic Anicijevic D., Gutic S., Vasic V., Skorodumova N.V. and Pasti I.A., The impact of structure of graphenebased materials on removal of organophosphorus pesticides from water, Environ. Sci.: Nano, 5, 14821494, (2018). https://doi.org/10.1039/c8en00171e

Li J., Wu Q., Wang X., Chai Z., Shi W., Hou J., Hayat T., Alsaedie A. and Wang X. Heteroaggregation behavior of graphene oxide on Zr-based metalorganic frameworks in aqueous solutions: a combined experimental and theoretical study. J. Mater. Chem. A, 5, 20398-20406, (2017). https:// doi.org/10.1007/s00128-015-1499-3

Li X., Li F., Gao Z. and Fang L. Toxicology of Graphene Oxide Nanosheets Against Paecilomyces catenlannulatus. B. Environ. Contam. Tox. 95, 25-30, (2015). https://doi.org/10.1007/s00128-015-1499-3

Li X. and Zhi L., Graphene hybridization for energy storage applications, Chem. Soc. Rev., 47, 31893216, (2018). https://doi.org/10.1039/c7cs00871f

Li X., Zhu C., Lu S. and Ma Y., Mass transfer of $\mathrm{SO}_{2}$ absorption with an instantaneous chemical reaction in a bubble column, Braz. J. Chem. Eng. 30, 551-562, (2013). https://doi.org/10.1590/s010466322013000300013
Liao C.F. and Siddoway M.A., Method and apparatus for removing particulate and gaseous pollutants from gas stream, TEK-KOL, US patent, $n$. 5,582,807, (1996).

Lilienthal H., Verwer C.M., van der Ven L.T.M., Piersma A.H. and Vos J.G., Exposure to tetrabromobisphenol A (TBBPA) in wistar rats: neurobehavioral effects in offspring from a one-generation reproduction study, Toxicology, 246, 45-54, (2008). https://doi. org/10.1016/j.tox.2008.01.007

Lin Y., Xu S. and Jia L., Fast and highly efficient tetracyclines removal from environmental waters by graphene oxide functionalized magnetic particles, Chem. Eng. J. 225, 679-685, (2013). https://doi.org/10.1016/j.cej.2013.03.104

Liu G., Li L., Xu D., Huang X., Xu X., Zheng S., Zhang Y. and Lin H., Metal-organic framework preparation using magnetic graphene oxide $\beta$-cyclodextrin for neonicotinoid pesticide adsorption and removal, Carbohydr. Polym. 175, 584-591, (2017). https:// doi.org/10.1016/j.carbpol.2017.06.074

Liu J., Fu S., Yuan B., Li Y., Deng Z., Toward a universal "adhesive nanosheet" for the assembly of multiple nanoparticles based on a protein-induced reduction/ decoration of graphene oxide, J. Am. Chem. Soc. 132, 7279-7281, (2010). https://doi.org/10.1021/ja100938r

Liu X., Hong H., Wu X., Wu Y., Ma Y., Guan W. and $\mathrm{Ye} \mathrm{Y}$., Synthesis of $\mathrm{TiO}_{2}$-reduced graphene oxide nanocomposites for efficient adsorption and photodegradation of herbicides, Water Air Soil Pol. 227, 21, (2016). https://doi.org/10.1007/s11270-015-2719-5

Liu Y., Tang N., Wan X., Feng Q., Li M., Xu Q., Liu F. and $\mathrm{Du}$ Y., Realization of ferromagnetic graphene oxide with high magnetization by doping graphene oxide with nitrogen, Sci. Rep. 3, 2566, (2013). https://doi.org/10.1038/srep02566

Liu Y., Ma Y., Guang S.Y., Ke F.Y. and Xu H.Y., Polyaniline-graphene composites with a threedimensional array-based nanostructure for highperformance supercapacitors, Carbon, 83, 79-89, (2015). https://doi.org/10.1016/j.carbon.2014.11.026

Luo Y., Jiang S., Xiao Q., Chen C. and Buyin Li B., Highly reusable and superhydrophobic spongy graphene aerogels for efficient oil/ water separation, Sci. Rep. 7, 7162, (2017). https://doi.org/10.1038/ s41598-017-07583-0

Ma J., Yang M., Yu F. and Zheng J., Water-enhanced removal of ciprofloxacin from water by porous graphene hydrogel, Sci. Rep. 5, 13578, (2015). https://doi.org/10.1038/srep13578

Ma J., Wang X., Liu Y., Wu T., Liu Y., Guo Y., Li R., Sun X., Wu F., Li C. and Gao J., Reduction of graphene oxide with L-lysine to prepare reduced graphene oxide stabilized with polysaccharide polyelectrolyte, J. Mater. Chem. A, 1, 2192-2201, (2013a). https://doi.org/10.1039/c2ta00340f 
Ma L.J., Yang X.M., Gao L.F., Lu M., Guo C.X., Li Y.W., Tu Y.F. and Zhu X.L., Synthesis and characterization of polymer grafted graphene oxide sheets using a $\mathrm{Ce}(\mathrm{IV}) / \mathrm{HNO}_{3}$ redox system in an aqueous solution, Carbon, 53, 269-276, (2013b). https://doi.org/10.1016/j.carbon.2012.10.058

Mabayoje O., Seredych M. and Bandosz T.J., Enhanced reactive adsorption of hydrogen sulfide on the composites of graphene/graphite oxide with Copper (Hydr)Oxychlorides, ACS Appl. Mater. Interfaces, 4 (6), 3316-3324, (2012). https://doi. org/10.1021/am300702a

Mahmoud A.E., Stolle A. and Stelter M. Sustainable synthesis of high-surface-area graphite oxide via dry ball milling. ACS Sustainable Chem. Eng. 6, 6358-6369, (2018). https://doi.org/10.1021/ acssuschemeng.8b00147

Mahmoodi N.M., Ghezelbash M., Shabanian M., Aryanasab F. and Saeb M.R. Efficient removal of cationic dyes from colored wastewaters by dithiocarbamate-functionalized graphene oxide nanosheets: From synthesis to detailed kinetics studies, J. Taiwan Inst. Chem. Eng. 81, 239-246, (2017). https://doi.org/10.1016/j.jtice.2017.10.011

Mahmoudian L., Rashidi A.L., Dehghani H. and Rahighi R., Single-step scalable synthesis of threedimensional highly porousgraphene with favorable methane adsorption, Chem. Eng. J. 304, 784-792, (2016). https://doi.org/10.1016/j.cej.2016.07.015

Malbrunot P., Vidal D. and Vermesse J., Storage of gases at room temperature by adsorption at high pressure, Appl. Thermal Eng. 16, 375-382, (1996). https://doi.org/10.1016/1359-4311(95)00018-6

Maliyekkal S.M., Sreeprasad T.S., Krishnan D., Kouser S., Mishra A.K., Waghmare U.V., and Pradeep T., Graphene: a reusable substrate for unprecedented adsorption of pesticides, Small, 9, 273-283, (2013). https://doi.org/10.1002/smll.201201125

McAllister M. J., Li J. L., Adamson D. H., Schniepp H. C., Abdala A. A., Liu, J., Herrera-Alonso M., Milius D. L., Car R., Prud'homme R. K. and Aksay I. A., Single sheet functionalized graphene by oxidation and thermal expansion of graphite. Chem. Mater. 19, 4396-4404, (2007). https://doi. org $/ 10.1021 / \mathrm{cm} 0630800$

McCoy T.M., Brown P., Eastoe, J. and Tabor R.F. Noncovalent Magnetic Control and Reversible Recovery of Graphene Oxide Using Iron Oxide and Magnetic Surfactants. ACS Appl. Mater. Interfaces, 7, 2124-2133, (2015). https://doi.org/10.1021/ am508565d

Merlin C., Bonot S., Courtois S. and Block J.C., Persistence and dissemination of the multipleantibiotic-resistance plasmid pB10 in the microbial communities' of wastewater sludge microcosms. Water Res. 45, 2897-2905, (2011). https://doi. org/10.1016/j.watres.2011.03.002
Mircescu N.E., Oltean M., Chis V. and Leopold N., FTIR, FT-Raman, SERS and DFT study on melamine, Vib. Spectrosc. 62, 165-171, (2012). https://doi.org/10.1016/j.vibspec.2012.04.008

Mishra A.K. and Ramaprabhu S., Enhanced $\mathrm{CO}_{2}$ capture in $\mathrm{Fe}_{3} \mathrm{O}_{4}$-graphene nanocomposite by physicochemical adsorption, J. Appl. Phys. 116, 064306.S, (2014). https://doi. org/10.1063/1.4892458

Mishra A.K. and Ramaprabhu S., Nanostructured polyaniline decorated graphene sheets for reversible $\mathrm{CO}_{2}$ capture, J. Mater. Chem. 22, 37083712, (2012). https://doi.org/10.1039/c2jm15385h

Montebello A.M., Fernández M., Almenglo F., Ramírez M., Cantero D., Baeza M. and Gabriel D., Simultaneous methylmercaptan and hydrogen sulfide removal in the desulfurization of biogas in aerobic and anoxic biotrickling filters, Chem. Eng. J. 200-202 237-246, (2012). https://doi. org/10.1016/j.cej.2012.06.043

Montes-Navajas P., Asenjo N.G., Santamaría R., Menéndez R., Corma A. and García H., Surface area measurement of graphene oxide in aqueous solutions, Langmuir, 29, 13443-13448, (2013). https://doi.org/10.1021/la4029904

Moussavi G., Hossaini Z. and Pourakbar M., Highrate adsorption of acetaminophen from the contaminated water onto double-oxidized graphene oxide, Chem. Eng. J. 287, 665-673, (2016). https:// doi.org/10.1016/j.cej.2015.11.025

Mrlík M., Ilcíková M., Plachý T., Pavlínek V., Špitalský Z. and Mosnácek J., Graphene oxide reduction during surface-initiated atom transfer radical polymerization of glycidyl methacrylate: Controlling electro-responsive properties, Chem. Eng. J. 283, 717-720, (2016). https://doi. org/10.1016/j.cej.2015.08.013

Muñoz P.A.R., de Oliveira C.F.P., Amurin L.G., Rodriguez C.L.C., Nagaoka D.A., Tavares M.I.B., Domingues S.H., Andrade R.J.E. and Fechine G.J.M., Novel improvement in processing of polymer nanocomposite based on 2D materials as fillers, Express Polymer Letters, 12,930-945, (2018). https://doi.org/10.3144/expresspolymlett.2018.79

Muralikrishna S., Sureshkumar K., Yan Z., Fernandez C. and Ramakrishnappa T., Non-enzymatic amperometric determination of glucose by $\mathrm{CuO}$ nanobelt graphene composite modified glassy carbon electrode, J. Braz. Chem. Soc. 8, 16321641, (2015). https://doi.org/10.5935/01035053.20150134

Muzyka R., Kwoka M., Smędowski Ł., Díez N. and Gryglewicz G., Oxidation of graphite by different modified Hummers methods, New Carbon Mater. 32, 15-20, (2017). https://doi.org/10.1016/j. carbon.2017.02.072 
Nag S., Duarte L., Bertrand E., Celton V., Castro M., Choudhary V., Guegan P. and Feller J.F., Ultrasensitive QRS made by supramolecular assembly of functionalized cyclodextrins and graphene for the detection of lung cancer VOC biomarkers, J. Mater. Chem. B, 2, 6571-6579, (2014). https://doi.org/10.1039/c4tb01041h

Nguyen D.D., Tai N.H., Lee S.B. and Kuo W.S., Superhydrophobic and superoleophilic properties of graphene-based sponges fabricated using a facile dip coating method, Energy Environ. Sci. 5, 79087912, (2012). https://doi.org/10.1039/c2ee21848h

Nodeh H.R., Ibrahim W.A.W., Kamboha M.A. and Sanagi M.M., Dispersive graphene-based silica coated magnetic nanoparticles as a new adsorbent for preconcentration of chlorinated pesticides from environmental water, RSC Adv. 5, 76424-76434, (2015). https://doi.org/10.1039/c5ra13450a

Novoselov K.S., Geim A.K., Morozov S.V., Jiang D., Zhang Y., Dubonos S.V., Grigorieva I.V. and Firsov A.A., Electric field effect in atomically thin carbon films, Science, 306, 666-669, (2004). https://doi. org/10.1126/science.1102896

Ogino I., Yokoyama Y., Iwamura S. and Mukai S.R., Exfoliation of graphite oxide in water without sonication: bridging length scales from nanosheets to macroscopic materials, Chem. Mater. 26, 33343339, (2014). https://doi.org/10.1021/cm501305c

Othman N.H., Alias N.H., Shahruddin M.Z., Abu Bakar N.F., Him N.R.N. and Lau W.J., Adsorption kinetics of methylene blue dyes onto magnetic graphene oxide, J. Environ. Chem. Eng. 6, 2803-2811, (2018). https://doi.org/10.1016/j.jece.2018.04.024

Pan S. and Aksay I.A., Factors controlling the size of graphene oxide sheets produced via the graphite oxide route, ACS Nano, 5, 4073-4083, (2011). https://doi.org/10.1021/nn200666r

Parviz D., Das S., Ahmed H.S., Irin F., Bhattacharia S. and Green M.J., Dispersions of non-covalently functionalized graphene with minimal stabilizer, ACS Nano, 6, 8857-8867, (2012). https://doi. org $/ 10.1021 / \mathrm{nn} 302784 \mathrm{~m}$

Paul B., Purkayastha D.D., Dhar S.S., Das S. and Haldar S., Facile one-pot strategy to prepare $\mathrm{Ag} / \mathrm{Fe}_{2} \mathrm{O}_{3}$ decorated reduced graphene oxide nanocomposite and its catalytic application in chemoselective reduction of nitroarenes, $\mathrm{J}$. Alloys Compd. 681, 316-323, (2016). https://doi. org/10.1016/j.jallcom.2016.04.229

Pena M.T., Casais M.C., Mejuto M.C., and Cela R., Development of an ionic liquid based dispersive liquid-liquid microextraction method for the analysis of polycyclic aromatic hydrocarbons in water samples, J. Chromatogr. A, 1216, 6356-6364, (2009). https://doi.org/10.1016/j. chroma.2009.07.032
Petit C., Mendoza B., and Bandosz T.J., Reactive adsorption of ammonia on Cu-based $\mathrm{MOF} /$ Graphene composites, Langmuir, 26, 15302-15309, (2010). https://doi.org/10.1021/la1021092

Petosa A.R., Jaisi D.P., Quevedo I.R., Elimelech M. and Tufenkji N., Aggregation and deposition of engineered nanomaterials in aquatic environments: role of physicochemical interactions, Environ. Sci. Technol. 44, 6532-6549, (2010). https://doi. org/10.1021/es100598h

Plechkova N.V. and Seddon K.R., Applications of ionic liquids in the chemical industry, Chem. Soc. Rev., 37, 123-150, (2008). https://doi.org/10.1039/ b006677j

PunethaV.D., RanaS., YooH.J.,ChaurasiaA., McLeskey Jr J.T., Ramasamy M.S., Sahoo N.G. and Cho J.W., Functionalization of carbon nanomaterials for advanced polymernanocomposites: A comparison study between CNT and graphene, Prog. Polym. Sci. 67, 1-47, (2017). https://doi.org/10.1016/j. progpolymsci.2016.12.010

Quang D.V., Hatton T.A. and Abu-Zahra M.R.M., Thermally stable amine-grafted adsorbent prepared by impregnating 3-aminopropyltriethoxysilane on mesoporous silica for $\mathrm{CO}_{2}$ capture, Ind. Eng. Chem. Res. 55, 7842-7852, (2016). https://doi. org/10.1021/acs.iecr.5b04096

Rahmani Z., Rashidi A.M., Kazemi A., Samadi M.T. and Rahmani A.R., N-doped reduced graphene oxide aerogel for the selective adsorption of oil pollutants from water: isotherm and kinetic study, J. Ind. Eng. Chem. 61, 416-426, (2018). https://doi. org/10.1016/j.jiec.2017.12.041

Ramanathan T., Fisher F.T., Ruoff R.S. and Brinson L.C., Amino-functionalized carbon nanotubes for binding to polymers and biological systems, Chem. Mater. 17, 1290-1295, (2005). https://doi. org $/ 10.1021 / \mathrm{cm} 048357 \mathrm{f}$

Rana S. and Jonnalagadda S.B., Synthesis and characterization of amine functionalized graphene oxide and scope as catalyst for Knoevenagel condensation reaction, Catal. Commun. 92, 31-34, (2017). https://doi.org/10.1016/j.catcom.2016.12.023

Ray S.K., Majumder C. and Saha P., Functionalized reduced graphene oxide (fRGO) for removal of fulvic acid contaminant, RSC Adv. 7, 2176821779, (2017). https://doi.org/10.1039/c7ra01069a

Razmkhah M., Moosavi F., Mosavian M.T.H. and Ahmadpour A., Tunable gas adsorption in graphene oxide framework, Appl. Surf. Sci. 443, 198-208, (2018). https://doi.org/10.1016/j. apsusc.2018.02.265

Ren X., Li J., Chen C., Gao Y., Chen D., Sue M., Alsaedi A. and Hayat T., Graphene analogues in the aquatic environment and porous media: Dispersion, aggregation, deposition and transformation, 
Environ. Sci.: Nano, 5, 1298-1340 (2018). https:// doi.org/10.1039/c7en01258f

Rivera-Utrilla J., Sánchez-Polo M., Ferro-García M.A., Prados-Joya G. and Ocampo-Pérez R., Pharmaceuticals as emerging contaminants and their removal from water. A review, Chemosphere. 93, 1268-1287, (2013). https://doi.org/10.1016/j. chemosphere.2013.07.059

Rostamian R. and Behnejad H., A comprehensive adsorption study and modeling of antibiotics as a pharmaceutical waste by graphene oxide nanosheets, Ecotoxicol. Environ. Saf. 147, 117-123, (2018). https://doi.org/10.1016/j.ecoenv.2017.08.019

Ruthven D., Principles of adsorption and adsorption process, New York, John Wiley and Sons, (1984).

Sadri R., Hosseini M., Kazi S.N., Bagheri S., Zubir N., Ahmadi G., Dahari M. and Zaharinie T., A novel, eco-friendly technique for covalent functionalization of graphene nanoplatelets and the potential of their nanofluids for heat transfer applications, Chem. Phys. Let. 675, 92-97, (2017). https://doi.org/10.1016/j.cplett.2017.02.077

Sainsbury T., Passarelli M., Naftaly M., Gnaniah S., Spencer S.J. and Pollard A.J., Covalent carbene functionalization of graphene: toward chemical bandgap manipulation, ACS Appl. Mater. Interfaces, 8, 4870-4877, (2016). https://doi. org/10.1021/acsami.5b10525

Sakakura T., Choi J.-C., Yasuda H., Transformation of carbon dioxide, Chem. Rev. 107, 2365-2387, (2007). https://doi.org/10.1021/cr068357u

Saleem H., Haneef M. and Abbasi H.Y., Synthesis route of reduced graphene oxide via thermal reduction of chemically exfoliated graphene oxide, Mater. Chem. Phys. 204, 1-7, (2018). https://doi. org/10.1016/j.matchemphys.2017.10.020

Sarfraz M. and Ba-Shammakh M., Harmonious interaction of incorporating CNTs and zeolitic imidazole frameworks into polysulfone to prepare high performance MMMs for $\mathrm{CO}_{2}$ separation from humidified post combustion gases, Braz. J. Chem. Eng. 35, 217-228, (2018). https://doi. org/10.1590/0104-6632.20180351s20150595

Scidà A., Haque S., Treossi E., Robinson A., Smerzi S., Ravesi S., Borini S. and Palermo V., Application of graphene-based flexible antennas in consumer electronic devices. Mater. Today, 21, 223-230, (2018). https://doi.org/10.1016/j. mattod.2018.01.007

Shan D., Deng S., Li J., Wang H., He C., Cagnetta G., Wang B., Wang Y., Huang J. and Yu G., Preparation of porous graphene oxide by chemically intercalating a rigid molecule for enhanced removal of typical pharmaceuticals, Carbon, 119, 101-109, (2017). https://doi.org/10.1016/j.carbon.2017.04.021
Shen J., Liu G.P., Huang K., Jin W.Q., Lee K.R. and $\mathrm{Xu}$ N.P., Membranes with fast and selective gastransport channels of laminar graphene oxide for efficient $\mathrm{CO}_{2}$ capture, Angew. Chem. Int. Ed. 54, 578-582, (2015). https://doi.org/10.1002/ ange. 201409563

Sheng Z., Song L., Zheng J., Hu D., He M., Zheng M., Gao G., Gong P., Zhang P., Ma Y. and Cai L., Protein-assisted fabrication of nano-reduced graphene oxide for combined in vivo photoacoustic imaging and photothermal therapy. Biomaterials, 34, 5236-5243, (2013). https://doi.org/10.1016/j. biomaterials.2013.03.090

Shi P. and Ye N., Investigation of the adsorption mechanism and preconcentration of sulfonamides using a porphyrin-functionalized $\mathrm{Fe}_{3} \mathrm{O}_{4}$-graphene oxidenanocomposite, Talanta, 143,219-225,(2015). https://doi.org/10.1016/j.talanta.2015.05.013

Shrivas K., Ghosale A., Nirmalkar N., Srivastava A., Singh S.K. and Shinde S.S., Removal of endrin and dieldrin isomeric pesticides through stereoselective adsorption behavior on the graphene oxidemagnetic nanoparticles, Env. Sci. Pollut. Res. 24, 24980-24988, (2017). https://doi.org/10.1007/ s11356-017-0159-z

Singh A. and Agrawal M., Acid rain and its ecological consequences, J. Environ. Biol. 29, 15-24, (2008).

Song Y., Cao L., Yu J., Zhang S., Chen S. and Jiang Y., Amino-functionalized graphene oxide blend with monoethanolamine for efficient carbon dioxide capture, J. Alloys Compd. 704, 245-253, (2017). https://doi.org/10.1016/j.jallcom.2017.01.310

Sophia C.A. and Lima E.C., Removal of emerging contaminants from the environment by adsorption, Ecotoxicol. Environ. Saf. 150, 1-17, (2018).

Soreanu G., Dixon M. and Darlington A., Botanical biofiltration of indoor gaseous pollutants - A minireview, Chem. Eng. J. 229, 585-594, (2013). https:// doi.org/10.1016/j.cej.2013.06.074

Stankovich S., Dikin D.A., Dommett G.H.B., Kohlhaas K.M., Zimney E.J., Stach E.A., Piner R.D., Nguyen S.T. and Ruoff R.S., Graphene-based composite materials, Nature, 442, 282-286, (2006). https:// doi.org/10.1038/nature04969

Staudenmaier L., Verfahren zur Darstellung der Graphitsäure. Ber. Dtsch. Chem. Ges. 31, 1481-1487, (1898). https://doi.org/10.1002/ cber. 18980310237

Su F.S., Lu C.Y., Chung A.J. and Liao C.H., $\mathrm{CO}_{2}$ capture with amine-loaded carbon nanotubes via a dual-column temperature/vacuum swing adsorption, Appl. Energ. 113, 706-712, (2014). https://doi.org/10.1016/j.apenergy.2013.08.001

Sun K., Dong S., Sun Y., Gao B., Du W., Xu H. and $\mathrm{Wu}$ J., Graphene oxide-facilitated transport of levofloxacin and ciprofloxacin in saturated and 
unsaturated porous media, J. Hazard. Mater. 348, 92-99, (2018). https://doi.org/10.1016/j. jhazmat.2018.01.032

Suo F., XieG., Zhang J., Li J., LiC., Liu X., Zhang Y., Mac Y. and Ji M., A carbonised sieve-like corn straw cellulosegraphene oxide composite for organophosphorus pesticide removal, RDC Adv. 8, 7735-7743, (2018). https://doi.org/10.1039/c7ra12898c

Tamilarasan P. and Ramaprabhu S., Integration of polymerized ionic liquid with graphene for enhanced $\mathrm{CO}$ adsorption, J. Mater. Chem. A, 3, 101-108, (2015). https://doi.org/10.1039/c4ta04808c

Tkalya E., Ghislandi M., Otten R., Lotya M., Alekseev A., van der Schoot P., Coleman J., de With G., and Koning C., Experimental and theoretical study of the influence of the state of dispersion of graphene on the percolation threshold of conductive graphene/polystyrene nanocomposites, ACS Appl. Mater. Interfaces, 6, 15113-15121 (2014). https:// doi.org/10.1021/am503238z

Vecera P., Chacón-Torres J.C., Pichler T., Reich S., Soni H.R., Görling A., Edelthalhammer K., Peterlik H., Hauke F. and Hirsch A., Precise determination of graphene functionalization by in situ Raman spectroscopy, Nat. Commun. 8, 1-9, (2017). https:// doi.org/10.1038/ncomms 15192

Velasco-Soto M.A., Perez-García S.A., AlvarezQuintana J., Cao Y., Nyborg L. and Licea-Jimenez L., Selective band gap manipulation of graphene oxide by its reduction with mild reagents, Carbon, 93, 967-973, (2015). https://doi.org/10.1016/j. carbon.2015.06.013

Velickovic Z.S., Marinkovic A.D., Bajic Z.J., Markovic J.M., Peric-Grujic A.A., Uskokovic P.S. and Ristic M.D., Oxidized and ethylenediaminefunctionalized multiwalled carbon nanotubes for the separation of low concentration arsenate from water, Sep. Sci. Technol. 48, 2047-2058, (2013). https://doi.org/10.1080/01496395.2013.790446

Vukovic G.D., Marinkovic A.D., Colic M., Ristic M.Đ., Aleksic R., Peric-Grujic A.A. and Uskokovic P.S., Removal of cadmium from aqueous solutions by oxidized and ethylenediamine-functionalized multi-walled carbon nanotubes, Chem. Eng. J. 157, 238-248, (2010). https://doi.org/10.1016/j. cej.2009.11.026

Wang L., Boutilier M.S.H., Kidambi P.R, Jang D., Hadjiconstantinou N.G. and Karnik R., Fundamental transport mechanisms, fabrication and potential applications of nanoporous atomically thin membranes, Nat. Nanotechnol. 12, 509-522, (2017a). https://doi.org/10.1038/nnano.2017.72

Wang Z., Li X., Liang H., Ning J., Zhou Z. and Li G. Equilibrium, kinetics and mechanism of $\mathrm{Au}^{3+}, \mathrm{Pd}^{2+}$ and $\mathrm{Ag}^{+}$ions adsorption from aqueous solutions by graphene oxide functionalized persimmon tannin.
Mater. Sci. Eng. C, 79, 227-236, (2017b). https:// doi.org/10.1016/j.msec.2017.05.038

Wang J., Salihi E.C. and Šiller L., Green reduction of graphene oxide using alanine, Mater. Sci.Eng. C, 72, 1-6, (2017c).

Wang J., Yu S., Zhao Y., Wang X., Wen T., Yang T., Ai Y., Chen Y., Hayat T., Alsaedi A. and Wang X. Experimental and theoretical studies of $\mathrm{ZnO}$ and $\mathrm{MgO}$ for the rapid coagulation of graphene oxide from aqueous solutions, Sep. Purif. Technol., 184, 88-96, (2017d). https://doi.org/10.1016/j. seppur.2017.03.058

Wang J., Li Y., Chen W., Peng J., Hu J., Chen Z., Wen T., Lu S., Chen Y., Hayat T., Ahmad B. and Wang $\mathrm{X}$., The rapid coagulation of graphene oxide on Ladoped layered double hydroxides, Chem. Eng. J., 309, 445-453, (2017e). https://doi.org/10.1016/j. cej.2016.10.053

Wang J., Wang X., Tan L., Chen Y., Hayat T., Hu J., Alsaedi A., Ahmad B., Guo W. and Wang X., Performances and mechanisms of $\mathrm{Mg} / \mathrm{Al}$ and $\mathrm{Ca} /$ Al layered double hydroxides for graphene oxide removal from aqueous solution, Chem. Eng. J., 297, 106-115, (2016a). https://doi.org/10.1016/j. cej.2016.04.012

Wang F., Yang B., Wang H., Song Q., Tan F. and Cao Y., Removal of ciprofloxacin from aqueous solution by a magnetic chitosan grafted graphene oxide composite, J. Molecular Liq. 222, 188-194, (2016b). https://doi.org/10.1016/j.molliq.2016.07.037

Wang S. and Wang X., Imidazolium ionic liquids, imidazolylidene heterocyclic carbenes, and zeolitic imidazolate frameworks for $\mathrm{CO}_{2}$ capture and photochemical reduction, Angew. Chem. Int. Ed. 55, 2308-2320, (2016). https://doi.org/10.1002/ anie. 201507145

Wang Y., Guan C., Wang K., Guo C.X. and Li C.M., Nitrogen, Hydrogen, Carbon Dioxide, and Water Vapor Sorption Properties of Three-Dimensional Graphene, J. Chem. Eng. Data. 56, 642-645, (2011). https://doi.org/10.1021/je100840n

Wanjeri V.W.O., Sheppard C.J., Prinsloo A.R.E., Ngila J.C. and Ndungu P.G., Isotherm and kinetic investigations on the adsorption of organophosphorus pesticides on graphene oxide based silica coated magnetic nanoparticles functionalized with 2-phenylethylamine, J. Environ. Chem. Eng. 6, 1333-1346, (2018). https:// doi.org/10.1016/j.jece.2018.01.064

Wu J.-B., Lin M.-L., Cong X., Liu H.-N. and Tan P.-H., Raman spectroscopy of graphene-based materials and its applications in related devices, Chem. Soc. Rev., 47, 1822, (2018).

Wu X.L., Meng L., Wu Y., Luk Y.-Y., Ma Y. and Du Y., Evaluation of graphene for dispersive solid-phase extraction of triazine and neonicotine pesticides 
from environmental water, J. Braz. Chem. Soc. 26, 131-139, (2015). https://doi.org/10.5935/01035053.20140227

Wu Z., Yuan X., Zhong H., Wang H., Zeng G., Chen X., Wang H., Zhang L. and Shao J., Enhanced adsorptive removal of $p$-nitrophenol from water by aluminum metal-organic framework/reduced graphene oxide composite, Sci. Rep. 6, 1-13, (2016). https://doi.org/10.1038/srep25638

Xia C., Li Y., Fei T. and Gong W., Facile one-pot synthesis of superhydrophobic reduced graphene oxide-coated polyurethane sponge at the presence of ethanol for oil-water separation, Chem. Eng. J. 345, 648-658, (2018). https://doi.org/10.1016/j. cej.2018.01.079

Xiang Z., Dai Q., Chen J.-F. and Dai L., Edge functionalization of graphene and two-dimensional covalent organic polymers for energy conversion and storage, Adv. Mater. 28, 6253-6261, (2016). https://doi.org/10.1002/adma.201505788

Xiao J., Lv W., Song Y. and Zheng Q., Graphene/ nanofiber aerogels: performance regulation towards multiple applications in dye adsorption and oil/ water separation, Chem. Eng. J. 338, 202-210, (2018). https://doi.org/10.1016/j.cej.2017.12.156

Xiao Y., Yuan H., Pang Y., Chen S., Zhu B., Zou D., Ma J., Yu L. and Li X., CO Removal from Biogas by Water Washing System, Chin. J. Chem. Eng. 22, 950-953, (2014). https://doi.org/10.1016/j. cjche.2014.06.001

$\mathrm{Xu}$ J., Wang L., and Zhu Y., Decontamination of bisphenol A from aqueous solution by graphene adsorption, Langmuir, 28, 8418-8425, 2012. https://doi.org/10.1021/la301476p

Xue J., Wang S., Han X., Wang Y., Hua X., Li J., Chitosan-functionalized graphene oxide enhancing the permeability and antifouling performance of polyvinylidene fluoride ultrafiltration membranes, Chem Eng. Technol. 41, 270-277, (2018). https:// doi.org/10.1002/ceat.201600709

Yang K., Chen B. and Zhu L., Graphene-coated materials using silica particles as a framework for highly efficient removal of aromatic pollutants in water, Sci. Rep. 5, 1-12, (2015). https://doi. org/10.1038/srep11641

Yang K., Li Y., Tan X., Peng R. and Liu Z. Behavior and Toxicity of Graphene and Its Functionalized Derivatives in Biological Systems. Small, 9, 1492-1503, (2013a). https://doi.org/10.1002/ smll.201201417

Yang R.T., Adsorbents: fundamentals and applications, John Willey and Sons, Hoboken (2003).

Yang, Zhan L., Xu X., Wang Y., Ling L. and Feng X., Graphene-based porous silica sheets impregnated with polyethyleneimine for superior $\mathrm{CO}_{2}$ capture, Adv. Mater. 25, 2130-2134, (2013b). https://doi. org/10.1002/adma.201204427
Yao W., Wang J., Wang P., Wang X., Yu S., Zou Y., Hou J., Hayat T., Alsaedi A., Wang X. Synergistic coagulation of GOand secondary adsorptionofheavy metal ions on $\mathrm{Ca} / \mathrm{Al}$ layered double hydroxides. Environ. Pollution, 229, 827-836, (2017). https:// doi.org/10.1016/j.envpol.2017.06.084

Ye R., Dong J.; Wang L., Mendoza-Cruz R., Li Y., An P.F., Yacamán M.J., Yakobson B.I, Chen D. and Tour J.M., Manganese deception on graphene and implications in catalysis, Carbon, 132, 623-631, (2018). https://doi.org/10.1016/j. carbon.2018.02.082

You S., Luzan S.M., Szabó T. and Talyzin A.V., Effect of synthesis method on solvation and exfoliation of graphite oxide, Carbon, 52, 171-180, (2013). https://doi.org/10.1016/j.carbon.2012.09.018

Yu J.-G., Yu L.-Y., Yang H., Liu Q. , Chen X.-H., Jiang X.-Y. Chen X.-Q., Jiao F.-P. Graphene nanosheets as novel adsorbents in adsorption, preconcentration and removal of gases, organic compounds and metal ions. Sci. Total. Environ., 502, 70-79, (2015). https://doi.org/10.1016/j.scitotenv.2014.08.077

Yu L., Wang L., Xu W., Chen L., Fu M., Wu J. and Ye D., Adsorption of VOCs on reduced graphene oxide, J. Environ. Sci. 61, 171-178, (2017). https:// doi.org/10.1016/j.jes.2017.08.022

Yu Y.S., Lu X., Ding H.M., Ma Y.Q., Computational investigation on DNA sequencing using functionalized graphene nanopores, Phys. Chem. Chem. Phys. 20, 9063-9069, (2018). https://doi. org/10.1039/c7cp07462j

Yuan X., Choi S.W., Jang E. and Lee K.B., Chemically activated microporous carbons derived from petroleum coke: Performance evaluation for $\mathrm{CF}_{4}$ adsorption, Chem. Eng. J. 336, 297-305, (2018). https://doi.org/10.1016/j.cej.2017.11.168

Yusuf M., Elfghi F.M., Zaidi S.A., Abdullah E.C. and Khan M.A., Applications of graphene and its derivatives as an adsorbent for heavy metal and dye removal: a systematic and comprehensive overview, RSC Adv. 5, 50392-50420, (2015). https://doi.org/10.1039/c5ra07223a

Zan W., Chemical functionalization of graphene by carbene cycloaddition: A density functional theory study, Appl. Surf. Sci. 311, 377-383, (2014). https:// doi.org/10.1016/j.apsusc.2014.05.071

Zeng Y., Yang Z., Li H., Hao Y., Liu C., Zhu L., Liu J., Lu B. and Li R., Multifunctional nanographene oxide for targeted gene-mediated thermochemotherapy of drugresistant tumour, Sci. Rep. 7, 1-10, (2017). https://doi.org/10.1038/srep43506

Zhang C., Zhang R.Z., Ma Y.Q., Guan W.B., Wu X.L., Liu X., Li H., Du Y.L. and Pan C.P., Preparation of cellulose/graphene composite and its applications for triazine pesticides adsorption from water, ACS Sustainable Chem. Eng. 3, 396-405, (2015). https:// doi.org/10.1021/sc500738k 
Zhang X., Gao B., Creamer A.E., Cao C. and Li Y., Adsorption of VOCs onto engineered carbon materials: A review, J. Hazard. Mater. 338, 102-123, (2017). https://doi.org/10.1016/j.jhazmat.2017.05.013

Zhang Z.J., Yao Z.Z., Xiang S.C. and Chen B.L., Perspective of microporous metalorganic frameworks for $\mathrm{CO}_{2}$ capture and separation, Energy Environ. Sci. 7, 2868-2899, (2014).

Zhao J., Liu C. and Ma J., A light-driven modulation of electric conductance through the adsorption of azobenzene onto silicon-doped- and pyridine-like $\mathrm{N}_{3}$-vacancy graphene, Nanoscale, 9, 19017-19025, (2017). https://doi.org/10.1039/c7nr07382h

Zhao X. and Liu P., Hydrophobic-polymer-grafted graphene oxide nanosheets as an easily separable adsorbent for the removal of tetrabromobisphenol A, Langmuir, 30, 13699-13706, (2014). https://doi. org/10.1021/la504077x

Zhao X., Duan H. and Li J., An evaluation on the environmental consequences of residual CFCs from obsolete household refrigerators in China, Waste Manag. 31, 555-560, (2011). https://doi. org/10.1016/j.wasman.2010.10.018

Zheng L.L., Pi F.W., Wang Y.F., Xu H., Zhang Y.Z. and Sun X.L., Photocatalytic degradation of acephate, omethoate, and methyl parathion by $\mathrm{Fe}_{3} \mathrm{O}_{4} @$ $\mathrm{SiO}_{2} @ \mathrm{mTiO}_{2}$ nanomicrospheres, J. Hazard. Mater. 315 , 11-22, (2016). https://doi.org/10.1016/j. jhazmat.2016.04.064

Zhou D., Cheng Q.-Y., Cui Y., Wang T., Li X. and Han B.-H., Graphene-terpyridine complex hybrid porous material for carbon dioxide adsorption, Carbon, 66, 592-598, (2014). https://doi.org/10.1016/j. carbon.2013.09.043
Zhou X., Huang W., Miao J., Xia Q., Zhang Z., Wang H. and Li Z., Enhanced separation performance of a novel composite material GrO@MIL-101 forCO/ $\mathrm{CH}_{4}$ binary mixture, Chem. Eng. J. 266, 339-344, (2015). https://doi.org/10.1016/j.cej.2014.12.021

Zhu H., Chen T., Liu J. and Da Li., Adsorption of tetracycline antibiotics from an aqueous solution onto graphene oxide/calcium alginate composite fibers, RSC Adv. 8, 2616-2621, (2018). https://doi. org/10.1039/c7ra11964j

Zhu Y.W., Shanthi Murali, Cai W.W., Li X.S., Suk J.W., Potts J.R. and Ruoff R.S., Graphene and graphene oxide: synthesis, properties, and applications, Small 22, 5226, (2010). https://doi.org/10.1002/ adma.201090156

Zhu Z.W. and Zheng Q.R., Methane adsorption on the graphene sheets, activated carbon and carbon black, Appl. Thermal Eng. 108, 605-613, (2016). https:// doi.org/10.1016/j.applthermaleng.2016.07.146

Zou Y., Wang X., Ai Y., Liu Y.-H., Li J.-X., Ji Y. and Wang X., Coagulation behavior of graphene oxide on nanocrystallined $\mathrm{Mg} / \mathrm{Al}$ layered double hydroxides: Batch experimental and theoretical calculation study, Environ. Sci. Technol., 50, 3658-3667, (2016a). https://doi.org/10.1021/acs. est.6b00255

Zou Y., Wang X., Ai Y., Liu Y., Ji Y., Wang H., Hayat T., Alsaedi A., Hu W. and Wang X. $\beta$-Cyclodextrin modified graphitic carbon nitride for the removal of pollutants from aqueous solution: experimental and theoretical calculation study. J. Mater. Chem. A. 4, 14170-14179, (2016b). https://doi.org/10.1039/ c6ta05958a 
